\title{
Multi agentes y autómatas celulares como base para el análisis eficaz y realista de la macroeconomía
}

\author{
Mario Ernesto Donoso Correa ${ }^{1,2}$ (D), Jorge Santiago Donoso Correa ${ }^{3}$ \\ ${ }^{1}$ Unidad de Ingeniería, Industria y Construcción, Universidad Católica de Cuenca, Ecuador. \\ ${ }^{2}$ Programa VLIR-IUC en Migración y Desarrollo Local, Universidad de Cuenca - Universidades \\ Flamencas, Bélgica. \\ ${ }^{3}$ Department of Web Development, Copenhagen School of Design and Technology, Dinamarca. \\ Autores para correspondencia: donoso.mario@gmail.com, santiagodonoso@gmail.com \\ Fecha de recepción: 26 de septiembre 2016 - Fecha de aceptación: 23 noviembre 2016
}

\section{RESUMEN}

A lo largo de la historia, muchas teorías económicas nacieron para tratar de resolver los problemas relacionados con la producción, el desempleo, la pobreza y la injusticia social. Algunas de estas doctrinas han sido apoyadas usando diferentes técnicas matemáticas, informáticas e incluso psicológicas. Este artículo presenta una propuesta no ortodoxa de desarrollo macroeconómico, con el gobierno como la columna vertebral de la inversión pública productiva, con el objetivo de mejorar la productividad y la competencia de los negocios; lo que resulta en un aumento del poder adquisitivo de la gente, más puestos de trabajo y distribución de la riqueza. Para la explicación del funcionamiento del ciclo económico de la propuesta y del comportamiento económico de los multi agentes, el manuscrito utiliza respectivamente las técnicas de creación de diagramas y autómata celular.

Palabras clave: Desarrollo económico, macroeconomía, diagramas de flujo, multi agentes, autómatas celulares.

\begin{abstract}
Throughout history many economic theories saw daylight that tried to solve problems related with production, unemployment, poverty and social injustice. Some of these doctrines have been supported using different mathematics, computer and even psychological techniques. This article presents an unorthodox proposal of macroeconomic development, with the government as backbone for productive public investment, and the objective to enhance productivity and business competition; which in turn leads to an increase in purchasing power of the people, more jobs and wealth distribution. For the explanation of the operation of the proposal's economic cycle and the economic behavior of the multi agents the manuscript used respectively the diagramming and cellular automaton techniques.
\end{abstract}

Keywords: Economic development, macroeconomics, flowcharts, multi agents, cellular automaton.

\section{INTRODUCCIÓN}

Este artículo se desarrolla en base a la pregunta que Yali (un nativo de Nueva Guinea) realizó al profesor Jared Diamond (1999), aunque la explicación no tiene nada que ver con el determinismo geográfico. En verdad, no solo un individuo, sino muchísimos hombres a lo largo de la historia se han preguntado cómo solucionar los distintos problemas que afectan a sus sociedades. Obviamente, tratar de entender y de resolver los fenómenos económicos que afligen a pequeñas comunidades, regiones y naciones ha sido muchas veces una prioridad. 
Esta misma pregunta es la que se está pretendiendo contestar en este artículo, pero a través de entender el funcionamiento del circuito económico con todos sus elementos y flujos. Solamente de esta manera se puede luego simular una sociedad virtual con sus respectivos procesos macroeconómicos, todo con el fin último de establecer sugerencias que podrían a futuro convertirse en políticas aplicables a las sociedades humanas.

Este estudio se basa en observar al sistema económico de la manera más objetiva posible, para así diagramarlo y luego simularlo, llegándose a programar un modelo que trasciende el nivel de sectores económicos (según el diagrama) para llegar al nivel individual de agentes, tal y como sucede en el mundo real. Esto, ya que son las múltiples interacciones a nivel microeconómico, aquellas que con el tiempo generan los patrones macroeconómicos que se observan y se miden en la realidad. Por último, se incluyen conclusiones y recomendaciones novedosas de carácter heterodoxo.

\subsection{La evolución en el pensamiento económico}

Según el materialismo histórico, en el cual se describe la división cronológica de acuerdo a los diferentes modos de producción (Starosta, 2015) hasta comienzos del siglo 20, el capitalismo evolucionó paulatinamente, a raíz de la Revolución Industrial, desde un capitalismo de tipo mercantil que duró más o menos doscientos años (desde el siglo 16 hasta el siglo 18). Antes del mercantilismo y durante toda la edad media (desde el siglo 6 hasta el siglo 15), el viejo mundo se caracterizó por tener reinos con un sistema feudalista de producción. Previamente, en el Mundo Antiguo había dominado el esclavismo (desde la Revolución Agrícola hace aproximadamente 10000 AC hasta el siglo 5); y, al inicio, cuando los seres humanos eran todavía nómadas, el sistema económico se basaba en la caza, pesca y recolección, denominándose comunidad primitiva.

Varios autores han propuesto numerosas formas de conocimientos macroeconómicos, utilizando para ello diversas teorías y métodos. En esta sección se pondrá especial énfasis en las metodologías de apoyo utilizadas en los estudios macroeconómicos como son: 1) la observación (Shapere, 1982) y consecuentemente su descripción textual; la experimentación (Guala, 2008), mediante políticas prácticas (con resultados alentadores y otros desastrosos) o a través de técnicas de la economía conductual (Urday, 2011); 2) modelos matemáticos y estadísticos o econométricos (Intriligator, 1978) que al aplicarlos en la realidad muchos han funcionado y otros no; 3) análisis de sistemas de redes (Jackson, 2008), donde se grafican los diferentes elementos y flujos económicos, y; 4) finalmente utilizando el poder de las computadoras a través de sistemas complejos (Tesfatsion \& Judd, 2006) donde se combina los diagramas obtenidos del análisis de redes con algoritmos lógicos o matemáticos (que contienen las ecuaciones de los modelos mencionados anteriormente).

En otras palabras, la economía al igual que muchas otras ciencias evolucionó desde simples teorías hasta el uso de las tecnologías más complejas (Skolnikoff, 1994), aunque se debe indicar que, en este caso concreto, siempre ocurrió su experimentación práctica en todas las sociedades humanas. De hecho, el progreso de las ciencias se da gracias a nuevas ideas que reformulan o sustituyen paradigmas anteriores; por otro lado, los novedosos descubrimientos científicos han logrado que existan más innovaciones tecnológicas, y estas a la vez han ayudado al progreso de la ciencia. Un ejemplo al respecto son los avances en el campo de la óptica, desde la época de Newton (Newton, 1979) y la invención de los telescopios (Van Helden, 1977) y microscopios (Wilson, 1995) en el siglo 17, instrumentos tecnológicos que colaboraron intensamente al desarrollo de la astronomía y de la microbiología. Lo mismo sucedió en el campo de la economía, aunque sin el uso de muchos instrumentos tecnológicos, a excepción de uno: la computadora con sus respectivos avances tanto en hardware como en software o programas especializados; es así que si se revisa cualquier libro sobre doctrinas económicas, se aprecia que los primeros textos fueron realizados por filósofos chinos (Hu, 1988), hindúes (Jha \& Jha, 1998), griegos (Lowry, 1979) y romanos (Frederiksen, 1975), los mismos que generaron simples teorías. Después, en el siglo 17, Sir William Petty (Petty, 1755) escribió algunas obras donde incluía tablas y cálculos estadísticos sobre demografía, economía, epidemiología y religión, entre las que se destaca, por ejemplo: "Essays on Mankind and Political Arithmetic" que fue publicada dos siglos después, en 1888, iniciándose así el periodo de la economía matemática a través de las estadísticas sociales. Luego, en el año 1759, François Quesnay (Quesnay, 1972) publicó su "Tableau économique" donde a través de un diagrama de flujos agrícolas y manufactureros entre diferentes elementos económicos, él formula 
el primer circuito económico. Posteriormente, entre 1832 y 1838, Aguste Walras (Hicks, 1934) y Antoine Augustin Cournot (Baloglou, 2012) escribieron sus obras tituladas: "De la nature de la richesse et de l'origine de la valeur" y "Recherches sur les principes mathématiques de la théorie des richesses" respectivamente, siendo ambas consideradas actualmente como estudios pioneros en econometría. Cournot en su mencionado libro demuestra a través de ecuaciones y gráficos matemáticos los procesos existentes en los cambios de precios y cantidades que generan un equilibrio de mercado en el caso del agua cuando existe un duopolio de oferta (Vives, 1984); trabajos como éste sirvieron de base para que posteriormente otros autores utilicen diferentes métodos matemáticos (Weintraub, 2008) como son análisis de regresiones (Naghshpour, 2012), ecuaciones diferenciales (Christiansen, 2002), modelos lineales (Chiang \& Wainwright, 2005), de optimización matemática (Intriligator, 1971), programación lineal y no lineal (Luenberger \& Ye, 1984), teoría de juegos (Rubinstein, 1990), etc. para demostrar así sus teorías. Grandes avances en el entendimiento de la ciencia económica se presentaron desde finales del siglo 19, destacándose los trabajos de Irving Fisher (Fischer, 1997) que luego desencadenaría en la creación de la primera sociedad econométrica a partir de 1930 (Bjerkholt, 1998) y en el nacimiento de la macroeconomía con métodos contables e indicadores modernos (Kuznets, 1937). Gracias a esto, se logró comprender, inventariar y crear índices del funcionamiento económico a nivel de todos los países del mundo, contabilidad que en la actualidad sigue en vigencia con pequeñas modificaciones. La nueva revolución en el campo de los estudios económicos empieza desde mediados del siglo 20, con la utilización de la segunda generación de computadoras (cuando los transistores reemplazaron a las válvulas termoiónicas) y la creación de programas especializados para estadísticas (Hill \& Toporek, 1979). Solamente a finales del siglo 20, y debido a la aparición de modernos microprocesadores y novedosos programas (Nikolai \& Madey, 2009) se empiezan a modelar sistemas dinámicos de diferentes tipos conformados por interacciones entre sus elementos, sean estos carros (Doniec et al., 2008), empresas (Conzelmann et al., 2005), personas (Benenson \& Torrens, 2004), etc. con la finalidad de imitar en lo posible el funcionamiento las sociedades humanas.

\subsection{La economía de mercado libre versus la economía de mando}

El siglo 20 se caracterizó por mantener dos sistemas económicos diferentes, formando dos grupos de países en el planeta, parcialmente aislados entre sí, e incluso muchas veces llegando al extremo de llegar a confrontaciones bélicas en naciones periféricas (Gaddis, 2006), causando la muerte de millones de personas.

Durante miles de años, pese a existir numerosos pensadores, jamás se había concretado en la realidad un sistema económico basado en ideas previas; más bien, como se mencionó anteriormente, las transformaciones se fueron dando poco a poco. Sin embargo, en 1917 esta situación cambió drásticamente con la Revolución Bolchevique en Rusia (Trotsky \& Eastman, 2008), ya que por primera vez en la historia de la humanidad un nuevo sistema económico basado en las ideas de los alemanes Karl Marx y Friedrich Engels fue puesto a prueba. A este sistema se le conoce con el nombre de socialismo y su posterior expansión a otros países afectó a un tercio de la población del mundo durante el siglo 20. Por otro lado, los países capitalistas más industrializados, pocos años después de la Gran Depresión de 1929, empezaron a modificar sus sistemas económicos basados nuevamente en ideas novedosas. Esta vez fueron las del británico John Maynard Keynes, basadas en una fuerte intervención e inversión gubernamental para así dinamizar la economía (Congdon, 2007), ya que el sector privado no podía recuperarse ni responder efectivamente a esta crisis.

Sin embargo, desde 1981 en Estados Unidos y desde 1983 en el Reino Unido, las ideas de pensadores como el austriaco Friedrich Hayeck (Wapshott, 2011) y sobre todo del estadounidense Milton Friedman (Hirsch \& De Marchi, 1991) empezaron a ser puestas a prueba por gobiernos denominados neoliberales. El propósito fue reducir el tamaño y la intervención de los gobiernos en la economía, aunque en la práctica los porcentajes de los presupuestos gubernamentales en relación al PIB en los países más desarrollados disminuyeron poco o nada, existiendo más bien sólo flexibilización al control del sistema financiero desde 1966 en adelante, y fuertemente a partir de 1991 (Barth et al., 2000), lo que provocó la gran recesión del año 2008. En todo caso, los países más afectados por adoptar este sistema bajo la recomendación del Banco Mundial y del Fondo Monetario Internacional fueron las naciones más pobres del planeta (Argent, 2007), ya que es bien conocido que el sector privado actuando 
unilateralmente tiene serias limitaciones para que las sociedades salgan del subdesarrollo. Estas limitaciones son las que precisamente se analizan en este estudio.

Por ende, es lógico que tanto el Marxismo como el Keynesianismo hayan considerado que los Estados deban intervenir necesariamente, para que por un lado se dinamice la economía, mientras que, por otro, exista una adecuada distribución de la riqueza. Obviamente, en el caso del socialismo, la concentración del patrimonio llegó a niveles inauditos en manos del sector público (Piketty et al., 2014) y de gobernantes corruptos, mientras que los ciudadanos de estos países tenían la prohibición legal de acumular incluso un patrimonio mínimo.

\subsection{Contribución del artículo}

La presente investigación consiste en un análisis eficaz y realista de la macroeconomía, cuyas observaciones, conclusiones y recomendaciones pueden ser aplicadas por gobiernos responsables de varios países con el fin de generar mejores condiciones de vida para sus poblaciones. La idea para realizar este estudio surgió de la curiosidad de los autores por encontrar soluciones para tratar de combatir problemas crónicos como son: los bajos niveles de empleo adecuado y la pobreza en muchas naciones del planeta.

Quizá una analogía interesante de estas propuestas se la puede encontrar en las políticas de Homefront (Harrison, 2000), sobre todo el hecho de que sean los gobiernos los que intervengan activamente en la economía creando empresas de gran tamaño que adoptaron tanto los países Aliados como las Potencias del Eje en el transcurso de la Segunda Guerra Mundial (1939-1945), con la diferencia que éstos incentivaron sobre todo el crecimiento de sus industrias bélicas de varias maneras: creando grandes fábricas estatales como las realizadas por la Unión Soviética, nacionalizando como fue el caso de Alemania, o con disminución de impuestos, subsidios, asesoramiento tecnológico y compras garantizadas por parte del Estado a empresas privadas como fue el caso de los Estados Unidos, consecuentemente concentrando riqueza en manos del Estado o de empresas privadas. La presente propuesta pretende que los gobiernos se involucren en la economía como si estuvieran simulando un contexto de guerra, pero no encaminada a combatir a países enemigos, sino más bien a producir bienes de consumo y, de ser factible, de capital. Todo esto, realizado de la manera más eficiente posible, para dinamizar sus mercados internos e incluso exportar, mientras que se distribuye la riqueza a la gente.

Obviamente, el hecho de que las simulaciones ofrezcan resultados satisfactorios en una computadora, no significa de ninguna manera que en la realidad éstos se vayan a repetir, ya que siempre los modelos son abstracciones cerradas y limitadas de la realidad, donde es imposible incluir todas las variables que generan la complejidad que muestran los sistemas económicos actuales. En todo caso, como ya se mencionó antes, constituye un adelanto enorme experimentar primero antes de aplicar políticas a sociedad reales. Por ende, si estas propuestas son aplicadas algún momento por algún gobierno, se recomienda que, al menor indicio de perjuicio a las poblaciones, estas sean revisadas de inmediato, pues se debe evitar posiciones dogmáticas que tanto sufrimiento y daño han generado a muchos hogares de varios países a lo largo de la historia.

\subsection{Estructura del artículo}

El presente estudio consiste: 1) en un recuento histórico de cómo ha ido evolucionando el pensamiento económico, a raíz que nuevas herramientas y técnicas de apoyo se van introduciendo al análisis con el transcurrir de los años; 2) luego, se diagraman los elementos y los flujos del sistema económico de manera general y sin hacer énfasis en un país en particular, con el propósito de entender el funcionamiento macro de cualquier economía en el planeta; 3) después, se realiza una simulación cerrada y limitada con respecto a la complejidad de la realidad y su sinnúmero de variables, utilizando la técnica de multi agentes encapsulados en autómatas celulares, para entender así el comportamiento de las micro interacciones de los actores económicos que finalmente generan macro-patrones; 4) de estas interrelaciones, se obtienen los polígonos de frecuencia de los elementos más relevantes al sistema, con su variabilidad en unidades monetarias y a lo largo tipo tiempo; 5) se analiza el porqué de estas fluctuaciones o cambios y se dan soluciones o alternativas que contribuyan a superar los trastornos económicos; y, por último 6) la investigación finaliza con conclusiones útiles y pertinentes. 


\section{CONCEPTUALIZACIÓN DE LA INTERACCIÓN ENTRE LAS ENTIDADES ECONÓMICAS}

El modelo de multi agentes realizado en este estudio, al igual que otros similares, está concebido sobre la base de diagramas creados a través del Lenguaje Unificado de Modelado o UML (Bergenti \& Poggi, 2000) y que luego fueron adaptados al lenguaje de programación Logo a través del software NetLogo. Los diagramas del presente estudio se basaron inicialmente en los modelos gráficos que representan los sistemas de redes de ASPEN, N-ABLE y EURACE@UNIBI, aunque los mismos fueron modificados posteriormente.

\subsection{Entidades económicas}

Se concibe un circuito económico entre siete elementos: sector primario, sector secundario, sector terciario, sector financiero, unidades de consumo, gobierno y resto del mundo. Cada uno contiene a varias entidades económicas (empresas, hogares e instituciones gubernamentales), los mismos que intercambian intrasectorialmente (entre agentes del mismo sector) e intersectorialmente (entre actores de diferentes sectores) siete diferentes tipos de flujos (Figura 1): bienes, servicios, dinero, laborales, información, energía y acciones-inmuebles. Además, existe un elemento estático (en color rojo) que corresponde a los recursos naturales, que son dependientes de las unidades de producción del sector primario para su explotación. El origen de los diferentes flujos (corresponde a elementos en color verde) y sus interconexiones con otros elementos dinámicos (en color azul) son las que hacen funcionar al circuito económico de acuerdo al modelo planteado.

\subsection{Flujos de bienes (Figura 1)}

Todos los bienes, ya sean de consumo o de capital (herramientas y máquinas usadas en los procesos productivos o de distribución), tienen su origen en unidades productivas del sector primario, a través de la explotación o extracción de los recursos naturales (Auty, 2001) (empresas de agricultura, ganadería, silvicultura, acuicultura, pesca, minería y obtención de petróleo y gas natural). Cuando se trata de alimentos, estos bienes muchas veces son comprados por comerciantes, quienes constituyen el mercado interno (Rugman, 1981). Caso contrario, si se trata de materias primas, éstas pasan al sector secundario, donde sus unidades de producción a través de encadenamientos industriales (Towill, 1996) los transforman en productos semielaborados o en bienes terminados finales. Posteriormente estos artículos también son vendidos a unidades de distribución en el sector terciario (comerciantes); y, a donde acuden los hogares (unidades de consumo) para adquirirlos de acuerdo a sus necesidades. Algunas empresas logran incluso exportar los productos nacionales, así como también de otros países provienen flujos de productos importados (Ohlin, 1952). Otros consumidores de bienes son el gobierno y el sector financiero (Mishkin, 2007). También algunos bienes se mueven en sentido opuesto, del sector secundario o terciario al sector primario, por ejemplo, los insumos fitosanitarios para las actividades agrícolas o máquinas que son transferidas al sector primario. Cuando existen contratos directos entre empresas de los distintos sectores de la producción o con el gobierno, a veces se puede omitir a los comerciantes del sector terciario, tal como sucede también con importaciones directas o exportaciones directas de empresas nacionales a internacionales. Los hogares también muchas veces evaden a los comerciantes cuando traen sus productos directamente desde el exterior. Otra forma de comprar o vender ciertos bienes es a través de las bolsas de valores, donde de acuerdo a la oferta y a la demanda se cotizan los precios internacionales de ciertos productos (Mishkin, 2007) de gran demanda mundial como, p.e., el petróleo, el oro o el cacao.

A través de las cadenas de producción y luego de distribución (Erengüç et al., 1999) se producen transformaciones, es así que las materias primas pasan a ser productos semielaborados y éstos últimamente se convierten en bienes finales, razón por la cual van adquiriendo más y más valor agregado (Christopher, 2005) (es el resultado de sumar todos los costos existentes en los diferentes procesos productivos más las utilidades de las unidades de producción y de distribución). Finalmente, a estos precios hay que agregar los impuestos, así como restar los subsidios (Bertrand \& Vanek, 1971) por parte de los gobiernos. 


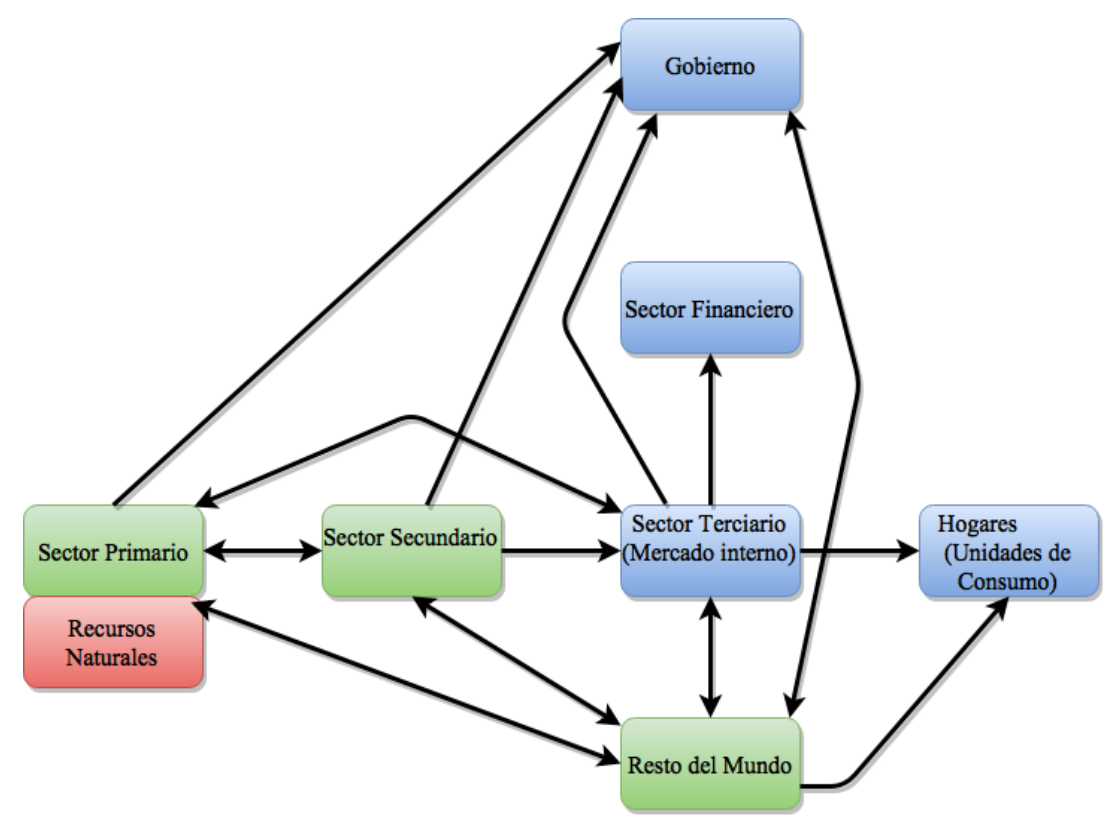

Figura 1. Flujos de bienes dentro del circuito económico.

\subsection{Flujos de servicios (Figura 2)}

Los flujos de servicios se refieren a la compra y venta de servicios profesionales (p.e., médicos o abogados), técnicos (p.e., mecánicos o electricistas) asesorías, consultorías, educación, desarrollo de software, investigación, etc. Estos flujos se originan principalmente en el sector terciario (servicios) o en las instituciones del gobierno, y de allí se desplazan a todas las unidades de producción, de distribución o de consumo que se encuentran inmersas dentro de los otros elementos del sistema económico (Fuchs, 1968). Es así que un hogar, por ejemplo, consume servicios médicos, de abogados, de odontólogos, de mecánicos, etc., mientras que una empresa consume servicios de técnicos, de auditores, etc. El gobierno necesita técnicos y consultores para a su vez prestar servicios a empresas y hogares (Elfring, 1988). De otros países del mundo también pueden venir asesores y técnicos a empresas o al gobierno, y de la misma manera, existen asesores y técnicos que salen temporalmente a otros países.

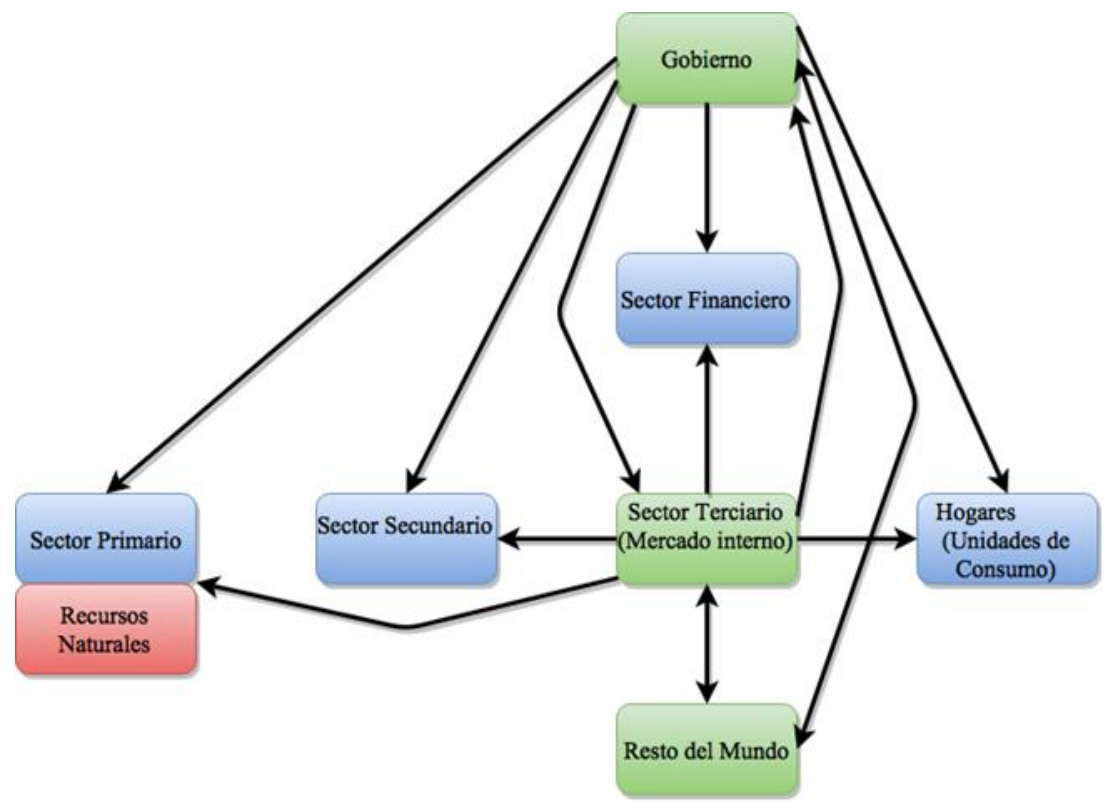

Figura 2. Flujos de servicios dentro del circuito económico. 


\subsection{Flujos monetarios (Figura 3)}

Los flujos monetarios son multidireccionales y se mueven en direcciones opuestas al resto de flujos, es decir que a cambio de energía, bienes, servicios, acciones, trabajo e información (aunque para ciertos tipos de informaciones hay acceso gratuito), siempre hay flujos de dinero como contraparte (Deleplace, 1996), pudiendo también direccionalizarse hacia y desde el sector financiero y gobierno sin intercambios como sucede con los ahorros, préstamos, impuestos, subsidios y pensiones de jubilados. Estos flujos se originan en el gobierno, donde existen instituciones dedicadas a la emisión monetaria (Fischer, 1982) como son los bancos centrales de cada país, luego a través del sistema bancario con préstamos basados en los depósitos existentes (descontando el porcentaje de encaje bancario) se genera el efecto multiplicador del dinero (McLeay et al., 2014). La oferta monetaria total distribuida inequitativamente entre los distintos actores económicos pertenecientes a los diferentes sectores del circuito sigue, en la mayoría de países, los lineamientos básicos de una ecuación basada en el valor total de bienes y servicios producidos dividido para la velocidad de circulación de los mismos. Esto se conoce como la teoría cuantitativa del dinero (Fischer, 1997) y generalmente se aplica con el fin de mantener procesos inflacionarios bajos y evitar por otra parte la deflación. Con el resto del mundo a través de la balanza de pagos (Allen, 1980) se registran todas las transacciones monetarias internacionales que tiene un país, y estas consisten en dinero que entra y sale por importaciones, exportaciones, sueldos, rentas, utilidades, inversiones, préstamos y donaciones. Además, se debe indicar que existe, entre naciones, continuos intercambios de divisas, cuyos precios fluctúan de acuerdo a las inflaciones existentes en los países del mundo y a la oferta y demanda por ciertos tipos de monedas (Cassel, 1916). Respecto a la aceptación y circulación del dinero electrónico o EFT (Guttmann, 2002) por sus siglas en inglés, estas consisten en tarjetas de crédito o de débito y transferencias electrónicas o tipo SWIFT (Langdale, 1985), mientras más desarrollado es el país, más dinero digital entre cuentas en servidores se moverá (Berentsen, 2005), y mientras más pobre es una nación, o en ciertas zonas rurales, estas economías funcionarán únicamente con billetes de papel o plástico y monedas metálicas.

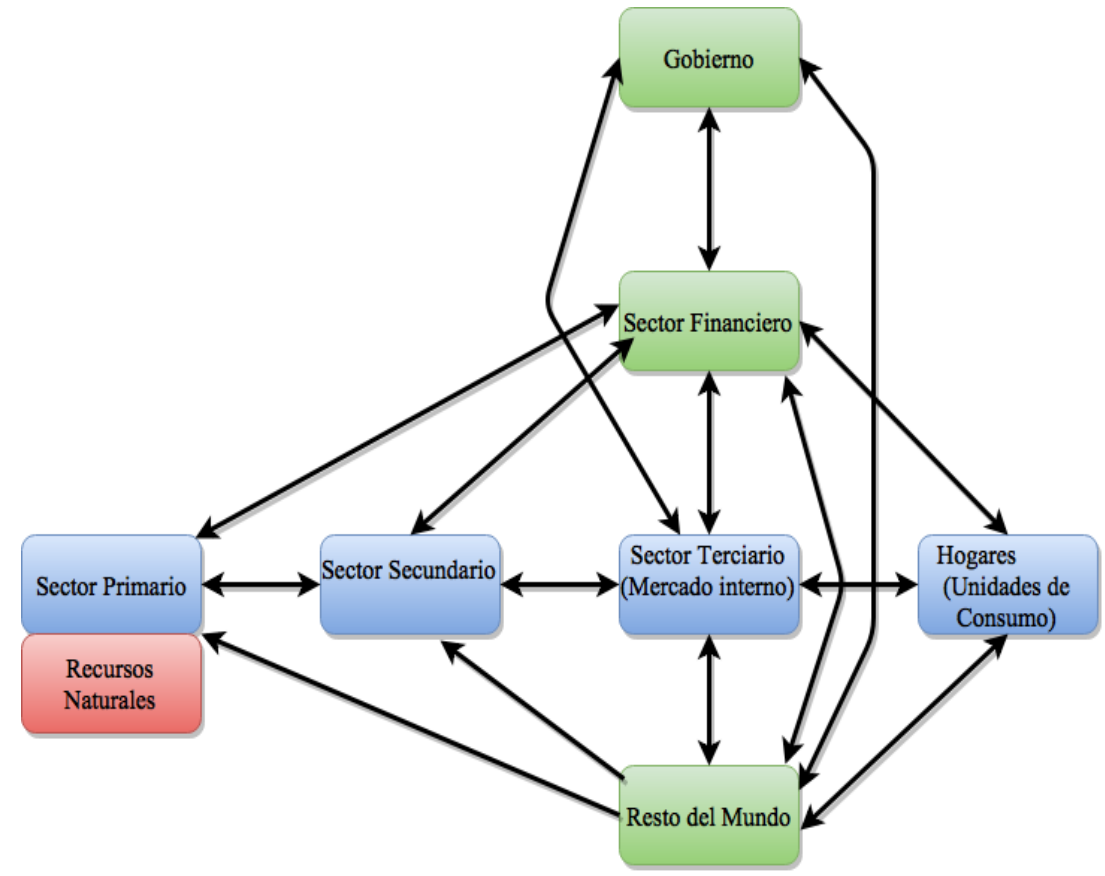

Figura 3. Flujos monetarios dentro del circuito económico.

\subsection{Flujos laborales (Figura 4)}

Los flujos laborales se refieren al movimiento de trabajadores, empleados, consultores, profesionales y dueños de las empresas desde sus hogares hacia las unidades de producción y de distribución ubicadas en los distintos elementos del modelo, así como también hacia las instituciones del gobierno central o gobiernos locales (Bhat et al., 2004). Existen además flujos laborales que salen del país o entran por servicios profesionales, técnicos o de consultoría de manera temporal, ya que, si fuesen flujos permanentes, estos equivaldrían a migración internacional. Estos flujos se caracterizan por recibir a 
cambio de trabajo, compensaciones monetarias como son dividendos o utilidades y, sueldos o salarios (Kreps, 1935). Estos flujos son dependientes del trabajo que generan las empresas de los sectores de la economía y de las instituciones públicas; y, a su inventario final se lo conoce como población económicamente activa (Hussmanns et al., 1990), conformada por las personas que tienen empleo adecuado, subempleados y desempleados. Estas dos últimas categorías son causadas por una sobre oferta de población (tasas de crecimiento demográfico elevadas) en relación a la demanda por la misma (tasas de crecimiento del Producto Interno Bruto o PIB muy bajas, nulas o negativas) y constituye un grave problema social (Miles, 1999).

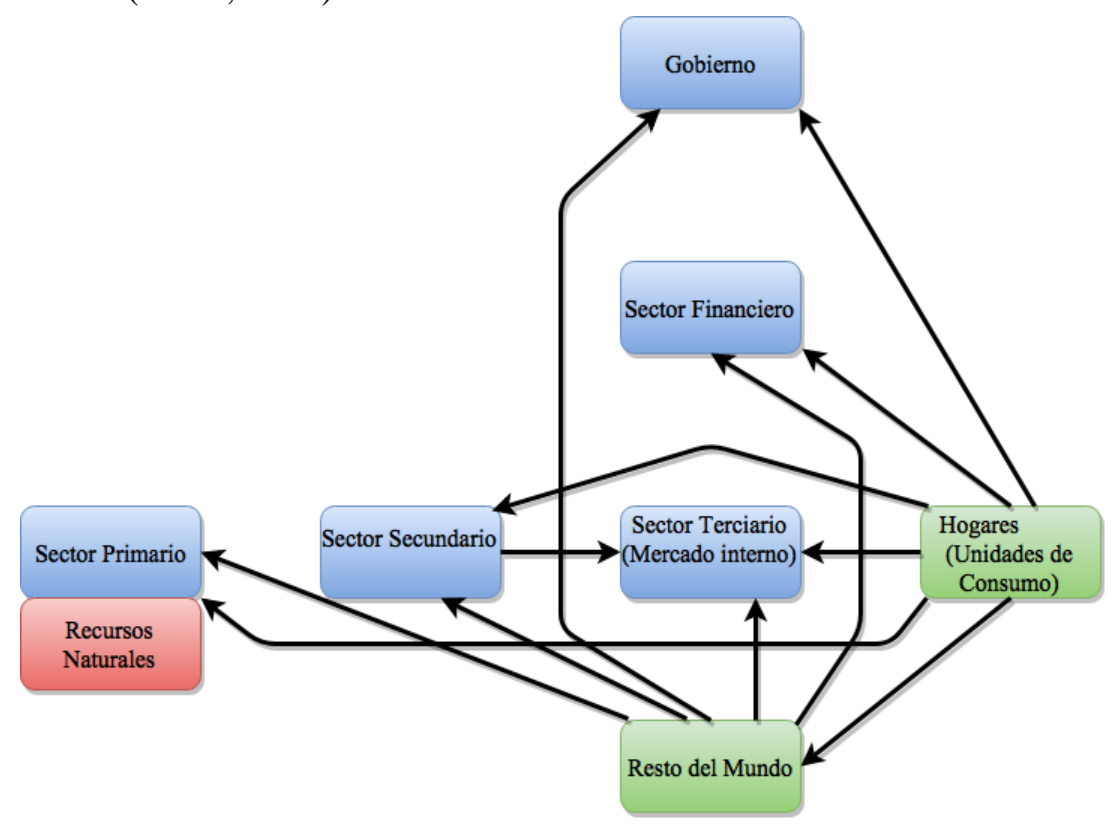

Figura 4. Flujos laborales dentro del circuito económico.

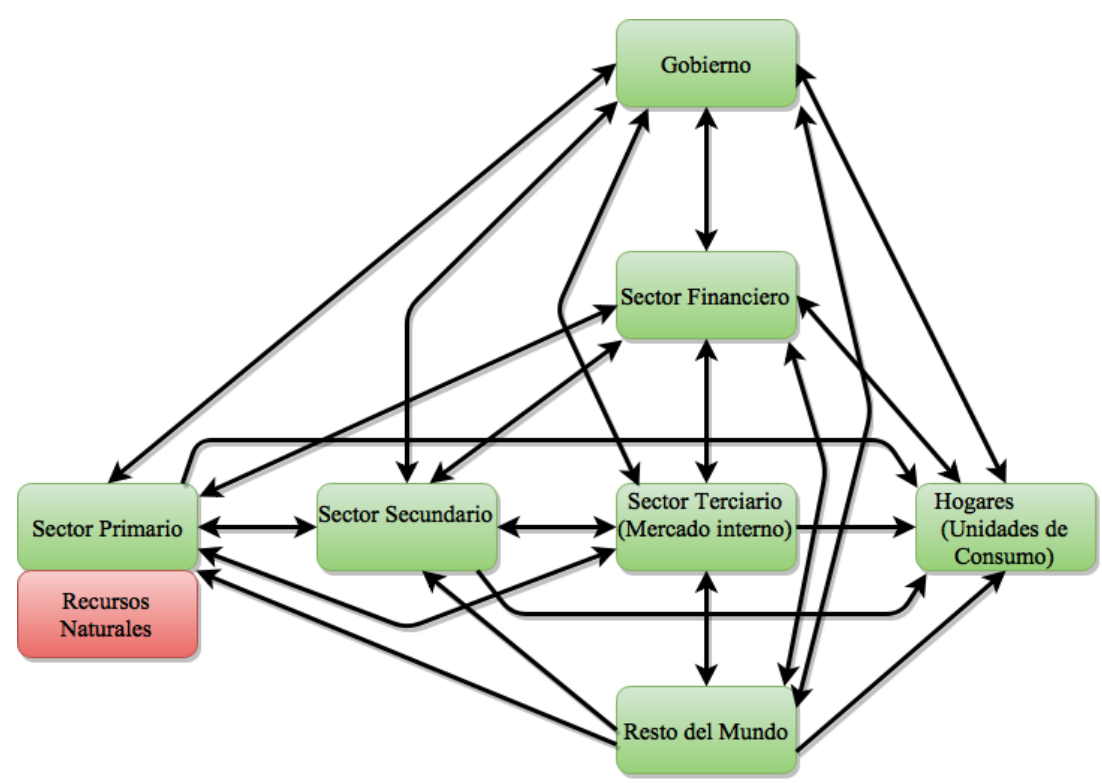

Figura 5. Flujos de información dentro del circuito económico.

\subsection{Flujos de información (Figura 5)}

Para los actores económicos, los flujos de información pueden ser de dos tipos: opcionales y obligatorios. Las propagandas (Smith, 1980) (empresarial o gubernamental), las noticias (Holden \& Subrahmanyam, 2002) (económicas, políticas, bursátiles, etc.), las estadísticas económicas y los libros y manuales técnicos (sobre producción y mercadeo) son flujos de información opcionales para la 
población; mientras que las leyes (Polinsky \& Shavell, 1999) (información tributaria, laboral, de sociedades, etc.) deben ser acatadas por las personas, ya que caso contrario existen penalidades (que van desde multas hasta la prisión). Todos estos flujos se transmiten de manera física a través de revistas, periódicos, etc. y de manera digital a través del internet, la televisión, la radio, redes celulares, etc. Estos flujos se originan en el Gobierno (leyes) o en empresas del sector terciario especializadas en recolectar noticias y crear propagandas. Aunque en las últimas dos décadas las empresas han ganado independencia gracias al internet y pueden hacer sus propias páginas web, otro medio de propaganda directa es a través de llamadas telefónicas. Por otra parte, todas las empresas de los diferentes sectores económicos y los hogares comparten información de ingresos, egresos y utilidades, así como de activos, pasivos y patrimonio de manera obligatoria con el gobierno central y con los gobiernos locales. En base a estos balances se fijan los impuestos (Laro \& Pratt, 2005) que por ley corresponde pagar a cada actor económico; de la misma manera, los bancos también solicitan este mismo tipo de información a las empresas y hogares para otorgar créditos (Saunders et al., 2006). La información tiene un efecto dinamizador o desdinamizador que afecta al resto de flujos del circuito económico (Conant, 1991); por ejemplo, si existen noticias de tensiones económicas o políticas, estas pueden generar desinversión, de la misma manera, aumentos en los niveles de empleo por un crecimiento sólido del PIB genera confianza en los inversionistas (Soroka, 2006).

\subsection{Flujos energéticos (Figura 6)}

Los flujos energéticos posibilitan que se produzcan los distintos procesos productivos, el funcionamiento de los hogares modernos y entidades gubernamentales, así como el transporte de los bienes.

La electricidad se obtiene del sector primario, transformando la energía mecánica de varias fuentes naturales (fuerza del agua y del viento) a electricidad a través de turbinas, a estos tipos de generación eléctrica se les denomina hidroeléctrica (Frey \& Linke, 2002), mareomotriz (Charlier \& Finkl, 2009) y eólica (European Wind Energy Association, 2009). También se obtiene electricidad en plantas termoeléctricas, usando el vapor de agua de fuentes naturales subterráneas (Armstead, 1978) (energía geotérmica), incinerando la biomasa (lignocelulosa) de los árboles y plantas (Field et al., 2008), a través de la combustión del carbón, derivados del petróleo y gas natural (Singer, 1981), con paneles termosolares o espejos solares (Müller-Steinhagen \& Trieb, 2004) o con reacciones de fisión nuclear (Novikov, 1958) (en plantas nucleares utilizando uranio radioactivo) y, en todos estos casos, el calor desprendido es utilizado para producir vapor de agua y esta fuerza mecánica se transforma a energía eléctrica a través del movimiento de turbinas o generadores. Finalmente, se produce energía eléctrica a través de paneles solares fotovoltaicos (Bube, 2012) (que pueden estar instalados en las cubiertas de los hogares o empresas), en los cuales los fotones chocan contra las placas de silicón cristalino desprendiendo electrones. Ultimamente, debido a la introducción de redes eléctricas inteligentes (Amin \& Wollenberg, 2005), estos flujos de electricidad pueden circular multi direccionalmente a través de todo el circuito económico.

Otro tipo de flujos de bienes con alta densidad energética son los que se utilizan en el transporte, concretamente los combustibles refinados del petróleo (Meyers, 2004) (originados en el sector secundario) como la gasolina, el diésel y el queroseno de jets más el gas (natural o licuado de petróleo) o aquellos de origen vegetal (Hill et al., 2006) como el etanol, el biodiesel y el biogás (Weiland, 2010), elaborados en industrias de productos agrícolas o basura orgánica y que hacen funcionar los motores de combustión interna de los diferentes medios de transporte terrestres, marítimos y aéreos. Se debe señalar que últimamente hay un porcentaje reducido de carros eléctricos que funcionan con baterías de iones de litio (Scrosati et al., 2011) y unos prototipos con hidrógeno líquido (Ahmed \& Krumpelt, 2001).

En la actualidad, hay otros tipos de energías experimentales, como es el uso de deuterio y tritio en plantas de fusión nuclear (Miller et al., 2004) para generar electricidad, así como el uso de organismos genéticamente modificados (Radakovits et al., 2010) (especialmente algas) para su posterior utilización como combustibles, baterías compuestas de nanomateriales novedosos (Whittingham, 2008) de alta densidad energética, el uso futuro de hidrato de metano (Lee \& Holder, 2001), entre otras posibilidades. 


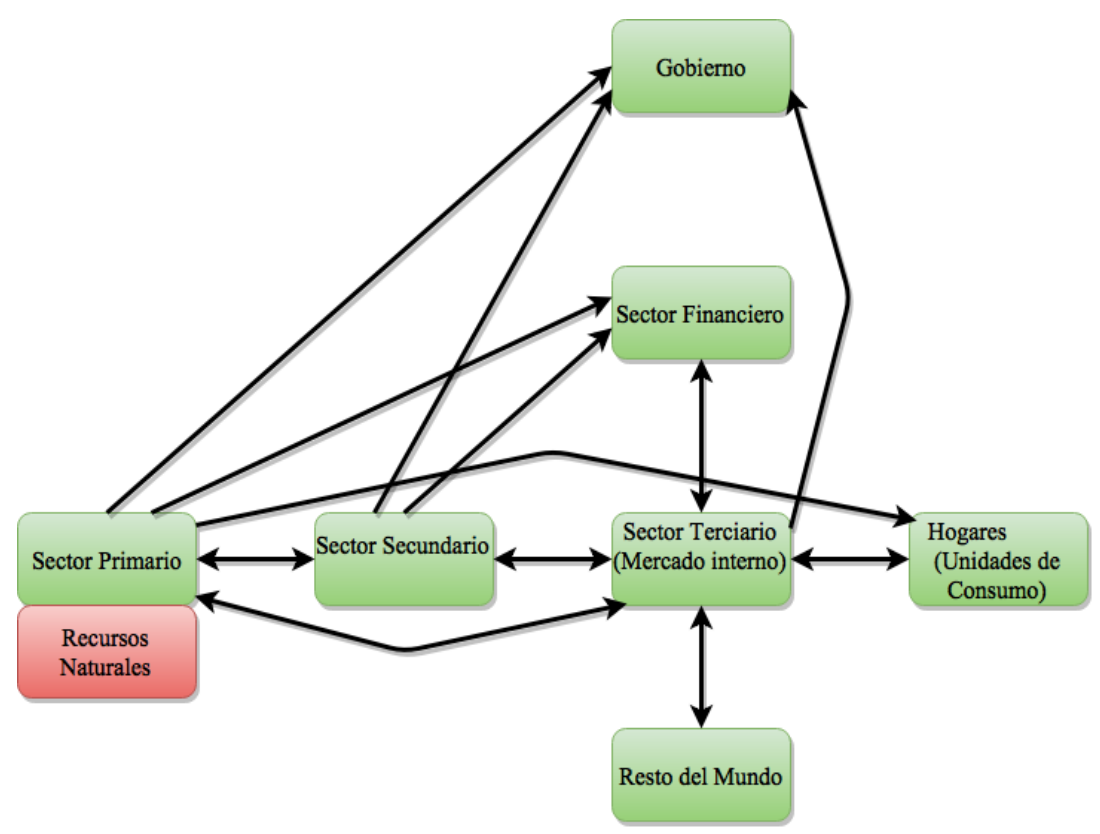

Figura 6. Flujos energéticos dentro del circuito económico.

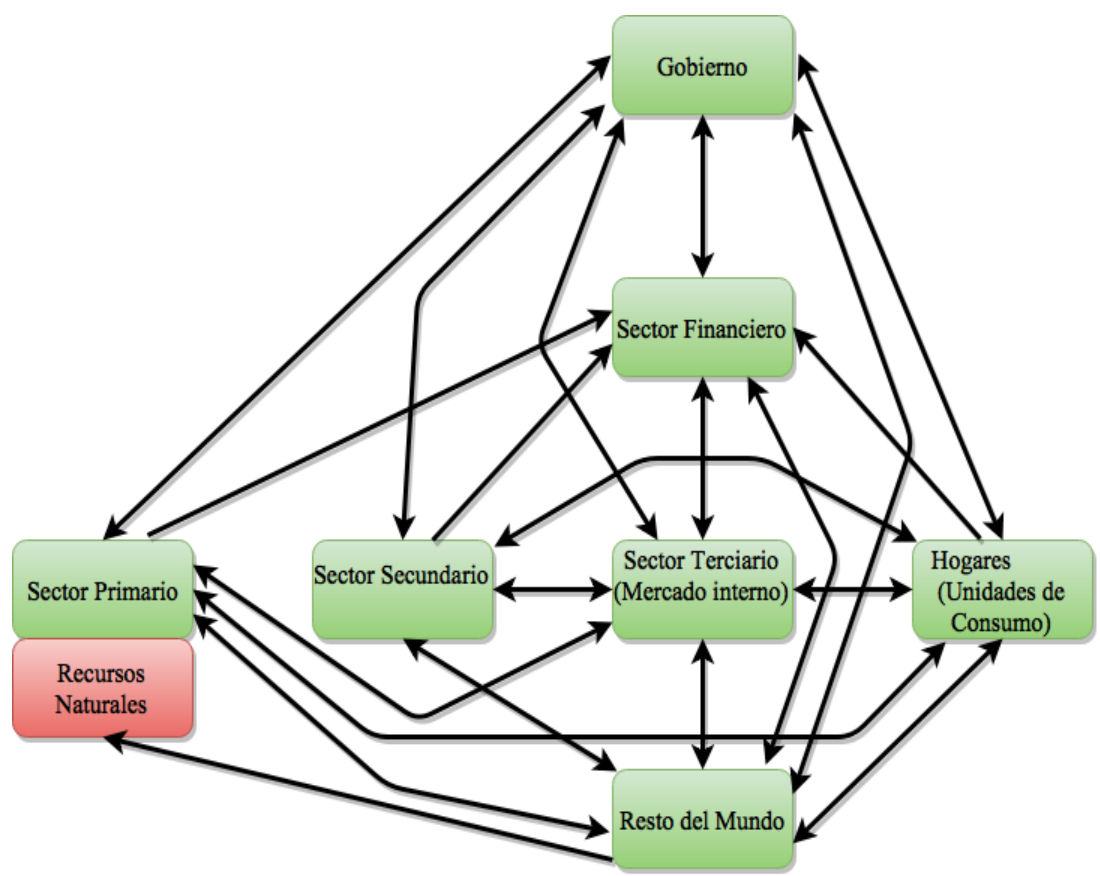

Figura 7. Flujos de acciones e inmuebles dentro del circuito económico.

\section{8. $\quad$ Flujos de acciones e inmuebles (Figura 7)}

Los flujos de acciones y bienes inmuebles (terrenos y unidades habitacionales realizados por la industria de la construcción) constituyen parte de los activos (que restando los pasivos da como resultado el patrimonio) y se originan en unidades (empresas y hogares) de cualquier elemento del circuito económico, consistiendo generalmente en compras-ventas de acciones de empresas que se dan a través de los mercados bursátiles (Levine \& Zervos, 1998) (sector terciario); o adquisiciones totales de empresas que se dan mediante negociaciones directas entre ellas. Sin embargo, éstas no son las únicas transacciones de este tipo de activos que se pueden dar, ya que también existen ventas de hipotecas completas o divididas en forma de obligaciones de deudas colaterales (Sumerlin \& Katzovitz, 2007). Es posible adquirir bienes raíces y bienes muebles a empresas y hogares, y el gobierno puede estatizar o expropiar (con o sin indemnizaciones), como también puede privatizar empresas estatales totalmente 
o parcialmente (Dewenter \& Malatesta, 1997) (empresas mixtas). Por su parte los bancos son capaces, a través de procesos judiciales, de ejecutar hipotecas u otros tipos de garantías y así adquirir activos. Además, compañías internacionales pueden adquirir empresas o acciones de las mismas dentro de un país, y viceversa (Dooley et al., 1987).

Todos estos elementos se plasman en el espacio geográfico, constituyendo los paisajes humanizados (Nicholson, 2000). Es así que las unidades de producción del sector primario constituyen unidades de producción agro-ganaderas y mineras de las zonas rurales, mientras que el resto de elementos conforman parte de los diferentes usos de suelo o zonas urbanas (Stull, 1974) residenciales, comerciales, de servicios, financieras, industriales y gubernamentales (pudiendo existir también áreas mixtas), a excepción del resto de países del mundo que obviamente trasciende los límites nacionales.

Se debe también señalar que para que se den todos los intercambios a través de los diferentes flujos del sistema económico, debe existir la infraestructura física necesaria que permita esta movilidad, así por ejemplo, los flujos de bienes y laborales (aunque últimamente hay ciertos empleos que se realizan desde las viviendas) siempre se materializan gracias a las calles, avenidas, autopistas, líneas férreas, canales, puertos y aeropuertos que hacen posible la circulación de carros, camiones, metros, trenes, barcos y aviones (Kessides, 1993); debiendo anotar que sólo pocos bienes se transportan por tuberías, como por ejemplo el agua (Mays, 1999). Los flujos de dinero, servicios, información, títulos de propiedad (ya sean de acciones o de bienes raíces) usan un sistema mixto, dado que personas, dinero físico, periódicos, revistas, leyes impresas y títulos impresos accionarios o de propiedad se transportan a través de la misma infraestructura y de los mismos medios de transporte utilizados para los flujos de productos y de trabajadores. Pero además, circulan de manera digital por cables de cobre y de fibra óptica (Keiser, 2003) (algunos desplazados a lo largo de los océanos del mundo) o por medio de telecomunicaciones analógicas o digitales (Greenstein \& Spiller, 1995) a través de antenas transmisoras y receptoras de ondas de radio (algunas ubicadas en satélites artificiales a miles de kilómetros del planeta Tierra); es así que existen comunicaciones telefónicas o de celulares, de radio, de fax, de televisión y de internet (las páginas web están almacenadas en servidores). Los flujos de energía eléctrica funcionan gracias a las redes eléctricas (Brown, 2008a) conformadas por alambres de cobre o aluminio y transformadores, mientras los combustibles líquidos (petróleo crudo o sus refinados) y gaseosos son transportados por oleoductos, gasoductos (Kennedy, 1993) y tanqueros (barcos y carros) hasta las respectivas estaciones de almacenaje o de expendio.

Todos los procesos productivos de bienes y los hogares producen desperdicios, igual sucede con los medios de transporte con motores de combustión interna. Si éstos son líquidos o cuasi-líquidos se eliminan a través de la infraestructura subterránea de desagües (Tchobanoglous \& Burton, 1991). Los desechos sólidos se eliminan mediante carros recolectores de basura y los gaseosos a través de chimeneas industriales y escapes vehiculares. Actualmente, hay varios métodos de purificación (parcial o total) y reciclaje de estos desechos, como son las plantas de tratamiento de agua (Droste, 1997) (a través de métodos químicos o biológicos), plantas recicladoras (Langenhoven \& Dyssel, 2007) de desechos orgánicos e inorgánicos (para metales, plásticos, vidrio, cartón y papel), y filtros de chimeneas industriales (Dullien, 1989) así como catalizadores (Kašpar et al., 2003) para automóviles, aviones, etc. Sin embargo, en muchos áreas rurales y ciudades del planeta todavía se sigue contaminando el medio ambiente a través de desagües que llegan a los ríos sin tratamiento, basurales y falta de utilización de filtros de gases contaminantes y tóxicos.

Se debe destacar además que es el gobierno a través de sus respectivas instituciones, mediante la creación de leyes y por medio de la emisión y regulación monetaria, quien se encarga de regular la economía de un país (Weingast, 1995), pudiendo además intervenir activamente en actividades productivas a través de empresas de propiedad estatal o mixtas (Xianhui \& Liansheng, 2009).

\section{ENFOQUE DE MULTI AGENTES Y DE AUTÓMATAS CELULARES}

Antes de nada, se debe indicar que estos modelos complejos de multi agentes y autómatas celulares son abstracciones de la realidad, y por ende es difícil recrear toda la complejidad y dinamismo existente en los diferentes sistemas del mundo físico, químico, biológico o social a través de modelos cerrados y por 
ende limitados (Richardson, 2003). En el caso específico de la economía, el gran inconveniente consiste en que desde 1934 (Copeland, 1937) se cuenta con inventarios agregados a través de indicadores macroeconómicos (Sims, 1980) que son válidos para conocer el comportamiento económico a nivel regional o nacional, pero al no existir estadísticas desagregadas a nivel de hogares, empresas o instituciones, se vuelve imposible entender las miles de interacciones entre los agentes económicos que a la larga conforman un circuito económico a nivel macro. Las alternativas para solucionar este problema, y dependiendo de la cantidad de dinero con el que cuenta el proyecto de investigación, consistirán en realizar muestreos a nivel de ciudades basados en encuestas a los actores económicos (Copeland, 1937) donde se determinen los flujos existentes entre ellos. También, se pueden realizar censos no sólo de inventarios de producción, sino de las relaciones comerciales y laborales existentes a nivel de cada empresa en pequeñas comunidades. Por último, se pueden establecer flujos agregados a nivel de subsectores de la economía. Los resultados estadísticos-contables (Healy \& Palepu, 2012) de estos estudios muestran los activos, pasivos, patrimonio, producción, gastos, egresos y utilidades a nivel individual de cada actor, así como también inventarios agregados a nivel de subsectores o sectores económicos (Wolfe, 1955). También y a diferencia de las estadísticas macroeconómicas clásicas, nos muestra cómo funciona la dinámica de flujos económicos a nivel de una comunidad o área urbana. En otras palabras, estos datos informan no solamente sobre los patrones macro, sino además qué procesos existen y cómo éstos dan lugar a la formación del sistema económico.

Ahora, comprender la situación real existente no es igual a calibrar los flujos (Fehler et al., 2004), aumentándolos o disminuyéndolos, para así mostrar escenarios alternativos con el fin último de generar recomendaciones que puedan posteriormente ser llevadas a la realidad mediante voluntad política y emisión de leyes que dinamicen o desestimulen ciertos tipos de flujos. Por esta razón es fundamental utilizar tecnologías modernas como es el caso de las simulaciones a través de multi agentes (Farmer \& Foley, 2009). Obviamente, cuando experimentamos en estos mundos virtuales, se ingresa al campo de las simulaciones sociales dentro de sociedades artificiales (Epstein \& Axtell, 1996); pero, ¿acaso no es más ético probar primero las doctrinas económicas en agentes compuestos de bits que no sienten, no sufren y por último, pueden desaparecer o ser eliminados del juego debido a políticas erradas creadas a través de algoritmos, antes que aplicar ideologías políticas (a veces interesantes en teoría pero absurdas en la práctica) a sociedades de personas, que al ser convertidas en leyes y puestas en rigor, afectan la vida de millones de seres humanos?

El presente estudio precisamente se basa en uno de estos programas de computadora basados en múltiples agentes, haciendo énfasis en un programa simple realizado en NetLogo (Tisue \& Wilensky, 2004) por los autores de este artículo. El mencionado software será analizado y comparado con dos megaproyectos concebidos para el diseño de políticas a nivel macro y que son de trascendental importancia para los Estados Unidos y la Unión Europea, denominados respectivamente: ASPEN (Basu et al., 1998) (A Microsimulation Model for the Economy) de Sandia National Laboratory (SNL) perteneciente al US Department of Energy (DOE), N-ABLE (Eidson \& Ehlen, 2005) (NISAC AgentBased Laboratory for Economics) creado por el National Infrastructure Simulation and Analysis Center, perteneciente al US Department of Homeland Security (DHS) en asociación con Los Alamos (LANL) y el previamente mencionado SNL y EURACE@UNIBI (Cincotti et al., 2012) basado en el programa FLAME (Deissenberg et al., 2008) (Flexible Large-scale Agent Modelling Environment) elaborado por EURACE (EURopean ACCredited Engineering).

Concretamente, a los diferentes actores económicos (empresas, instituciones públicas y hogares) se les puede representar a través de miles de multi agentes inteligentes que actúan entre ellos, y el resultado de estos micro-procesos crean macro-patrones estadísticos y espaciales (Fromm, 2006). Estos actores intercambian los siete tipos de flujos mencionados anteriormente, ya sea inter-sectorialmente o intra-sectorialmente. A continuación, se presenta un gráfico (Figura 8) que representa flujos de bienes entre cuatro Unidades de Producción Agropecuaria (UPAs) y de éstas con cuatro industrias, pudiéndose observar la interdependencia existente entre los sectores primario y secundario, así como los encadenamientos industriales (Liu \& Zhao, 2006) existentes.

Como ya se mencionó anteriormente, dentro del circuito económico, cada uno de los agentes en el mundo real intercambia bienes, servicios, dinero, trabajo, información, energía y acciones o inmuebles a cambio de dinero (con o sin intereses), contabilizándose macroeconómicamente únicamente el valor monetario (la sumatoria total de todos los precios por las cantidades) de todos estos flujos internamente 
a través del PIB (Obstfeld et al., 1996), así como solamente el valor monetario de todas las transacciones y transferencias internacionales de manera externa a través de la balanza de pagos (Meade, 1951). En otras palabras, dentro de las cuentas nacionales de todos los países del mundo, los únicos datos existentes se refieren a cantidades de dinero que corresponden de manera agregada a subsectores y sectores económicos, así como a montos monetarios de exportaciones e importaciones (también divididos en subsectores y sectores económicos) y transferencias de capital por inversiones, préstamos, pagos de amortizaciones, remesas, donaciones, etc. Lo que sucede en la contabilidad macroeconómica a nivel de cada actor económico es que, realmente se borran (en color rojo) los flujos de las cantidades medidas en diferentes unidades, y éstas son sustituidas por valores monetarios que son producto de la multiplicación de los precios finales por las cantidades mencionadas previamente (Okun, 1981).

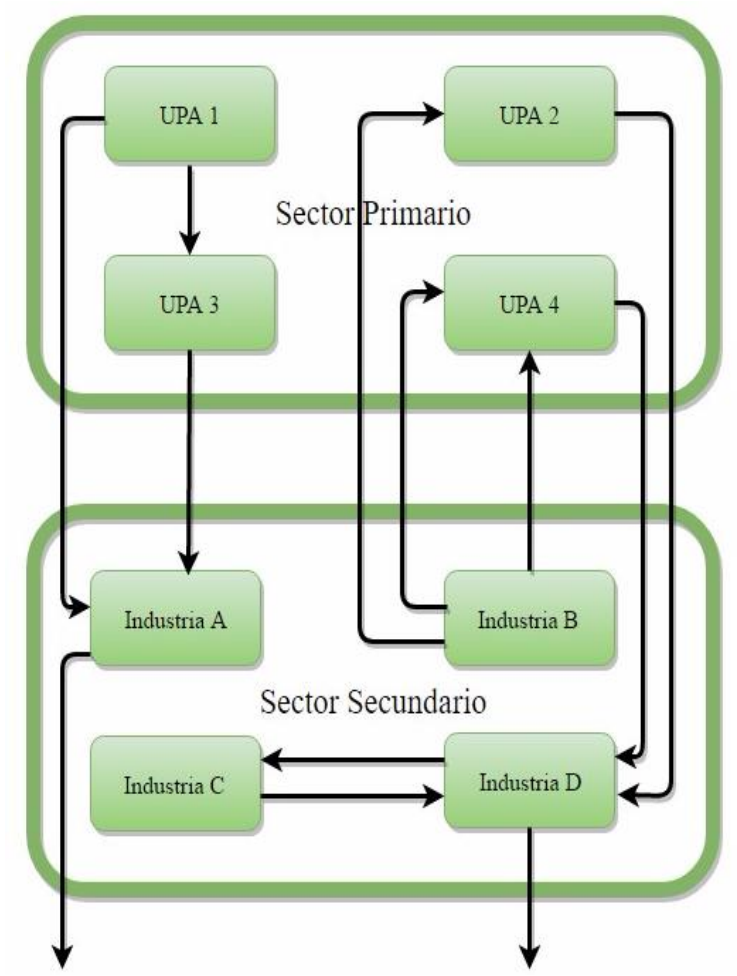

Figura 8. Flujos de bienes entre agentes económicos de los sectores primario y secundario.
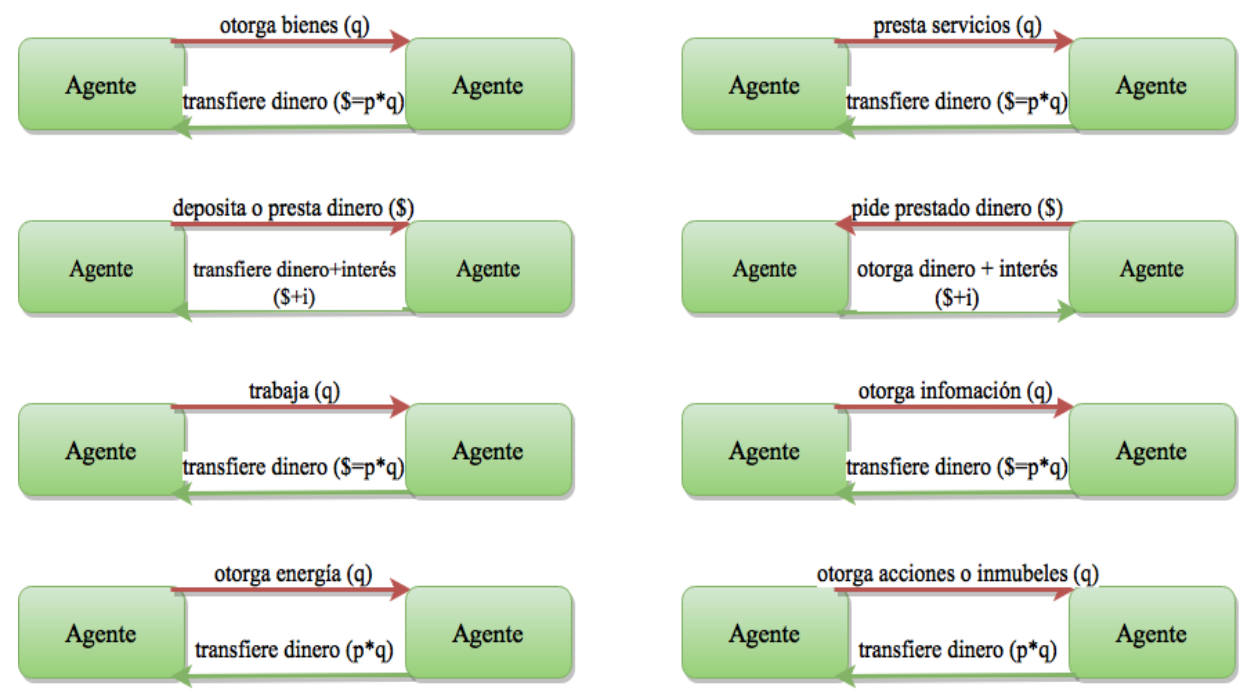

Figura 9. Flujos varios y flujos de dinero como contraparte entre varios agentes económicos. 


\subsection{Representación virtual de los agentes económicos}

Como simplificación de las complejas dinámicas del modelo económico, se optó por utilizar una combinación de multi agentes encapsulados dentro de autómatas celulares capaces de interactuar con uno, dos, cuatro (vecindario de Von Neumann) (Wolfram, 1983) u ocho vecinos (vecindario de Moore) (Weisstein, 2005) dentro de un modelo limitado a 10,000 células o celdas. Para diferenciar la influencia que cada tipo de empresa tiene en el mercado virtual, fue necesario categorizar en siete tipos de actores económicos de acuerdo a sus interacciones con sus celdas vecinas, es así que las empresas transnacionales, las instituciones gubernamentales (recaudadoras de impuestos y otorgadoras de subsidios) y los bancos, son capaces de interactuar con todos sus ocho vecinos. Las grandes compañías con cuatro celdas adyacentes, las medianas con dos células, y las pequeñas y los hogares interactúan siempre con un solo vecino (siempre y cuando éste no sea otro hogar). Por ende, el modelo representa en cada interacción de tiempo $t 1, t 2 \ldots$ tn un crecimiento geométrico o decrecimiento geométrico de unas empresas en relación a otras, teniendo las empresas más grandes mayores probabilidades de éxito (a no ser que se extingan en las primeras interacciones), ya que tienen más vecinos, mientras que la mayoría de las pequeñas pueden desaparecer al primer encuentro con otro vecino o mantenerse sin crecer en el tiempo.

\subsection{Funcionamiento interno de cada agente económico}

En el mundo real, cada actor económico tiene un cierto capital inicial (los agentes que representan empresas pequeñas se originan con una unidad monetaria, los que representan medianas con dos, los que representan a las grandes, con cuatro, y a las transnacionales se inician con ocho) y diariamente efectúa múltiples transacciones económicas y las registra a través de asientos contables que dan resultados anuales (Feroz et al., 2003), llamados estado de pérdidas y ganancias (evalúa las utilidades generadas resultantes de los ingresos menos los gastos) y estado de situación final (evalúa el patrimonio existente resultante de los activos menos los pasivos). Estas actividades se pueden representar también dentro de cada agente virtual por medio de reglas específicas de juego (Gilbert \& Terna, 2000) plasmadas en un diagrama en lenguaje UML, representando a través de un flujo que sale del agente (OUT) y que lleva un mensaje basado en una función de intercambio (puede ser cierta cantidad $q$ de unidades de algún tipo específico de flujo, sin que exista en este modelo una nomenclatura específica para diferenciarlos, ya que como se indicó antes, éstos no son inventariados macroeconómicamente. El intercambio se produce entre empresas adyacentes o vecinas: es decir, al contactar un agente a otro se genera un evento en el cual se intercambia alguna cantidad $q$ por dinero $(\$=p * q)$, donde al azar (usando iteraciones Monte Carlo de $+1,-1$ y 0 ) a veces una empresa puede ganar desde una unidad monetaria hasta ocho unidades monetarias y otras pueden perder desde una unidad monetaria hasta ocho unidades monetarias, llegando finalmente este flujo (IN) al agente virtual. Cada actor económico contiene además una memoria interna donde va sumando o restando los eventos monetarios generados al azar y se va enriqueciendo a medida que va ganando dinero, aunque a veces también llega a tener valores negativos y por ende éstas desaparecen del modelo, mientras que nuevas empresas son creadas en el siguiente evento de tiempo. En el modelo, los bancos funcionan de la misma manera que las transnacionales y estas compañías crediticias junto con las instituciones del Gobierno nunca desaparecen, independientemente de que existan valores negativos. Los hogares aparecen constantemente en grandes cantidades, otorgan su unidad monetaria a otro agente (perdiéndose el azar en estos casos) y desaparecen inmediatamente luego de hacerlo, manteniendo a las empresas y haciéndolas crecer. Se debe aclarar además que, como regla general, hogares vecinos no interactúan en esta simulación y por ende no desaparecen gran parte de éstos, ya que conforman las 3/4 partes del total de agentes. Finalmente, cuando una empresa pequeña logra adquirir dos unidades monetarias se transforma en mediana, si una mediana logra almacenar cuatro unidades se transforma en grande y si esta llega a tener ocho unidades se convierte en gigante.

\subsection{Modelización de la interacción entre multi agentes económicos}

La simulación espacial es muy difícil de entender e interpretar, consta de 10,000 agentes que se comportan de acuerdo a las reglas mencionadas anteriormente en el modelo de autómata celular, siendo los hogares los más numerosos, en tanto que hay bastantes empresas pequeñas, pocas medianas, muy 
pocos grandes y las transnacionales son escasas. Todas ellas compiten entre sí por obtener unidades monetarias y sobrevivir en el mercado. Se debe recalcar que la mayoría de los agentes corresponden a hogares (celdas rojas si están activos y celdas de color rojo periférico si están desapareciendo luego de entregar su unidad monetaria), y al no haber interacciones entre éstos, se atenúa la dinámica del sistema. Las empresas pequeñas están representadas por células azules si están activas y de color azul en su periferia si están inactivas. Este mismo tipo de representación se aplica a las empresas medianas activas y difuntas (en color verde), a las empresas grandes dentro y fuera del mercado (en color amarillo) y a las transnacionales (en color negro). Los bancos se representan en color café y las instituciones del gobierno en color blanco y siempre están activos (al existir pocos de estos dos tipos de agentes, son difíciles de distinguirlos visualmente dentro de todo el grupo).

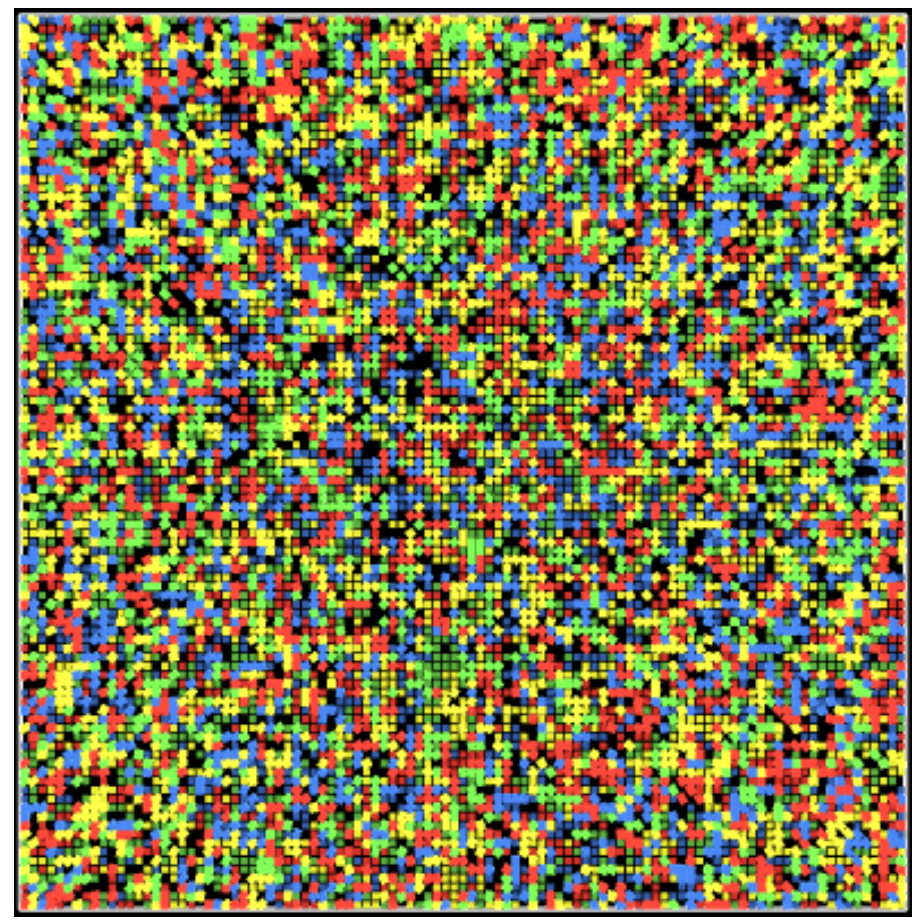

Figura 10. Interacciones de 10.0000 multi agentes encapsulados en autómatas celulares (cuadrícula de $100 \times 100$ celdas).

\section{RESULTADOS}

Las interacciones de multi agentes en el tiempo generaron varios resultados. Estos fueron representados a través de cuatro polígonos de frecuencia creados por las interacciones monetarias-temporales de los agentes de la simulación (Figuras 11, 12, 14 y 15). Del análisis de las mismas, se logró determinar valiosas conclusiones, así como novedosas recomendaciones. Cabe destacar que además se incluyeron dos estudios adicionales en este artículo sobre los beneficios de la banca pública (no modelado en este estudio) y otro respecto al PIB de acuerdo al gasto (modelado parcialmente, pero no representado gráficamente).

\subsection{Los hogares son los agentes más numerosos, por ende, a mayores niveles de consumo privado dinamizarán la economía}

Como se mencionó anteriormente, la mayoría de agentes corresponden a hogares en la simulación, tal y como sucede en el mundo real, puesto que la mayoría de personas no tienen empresas propias, con excepción de países muy pobres con altos niveles de subempleo y sin beneficios de desempleo, donde 
un alto porcentaje de individuos están obligados a vender cualquier objeto para lograr sobrevivir ellos y sus familias.

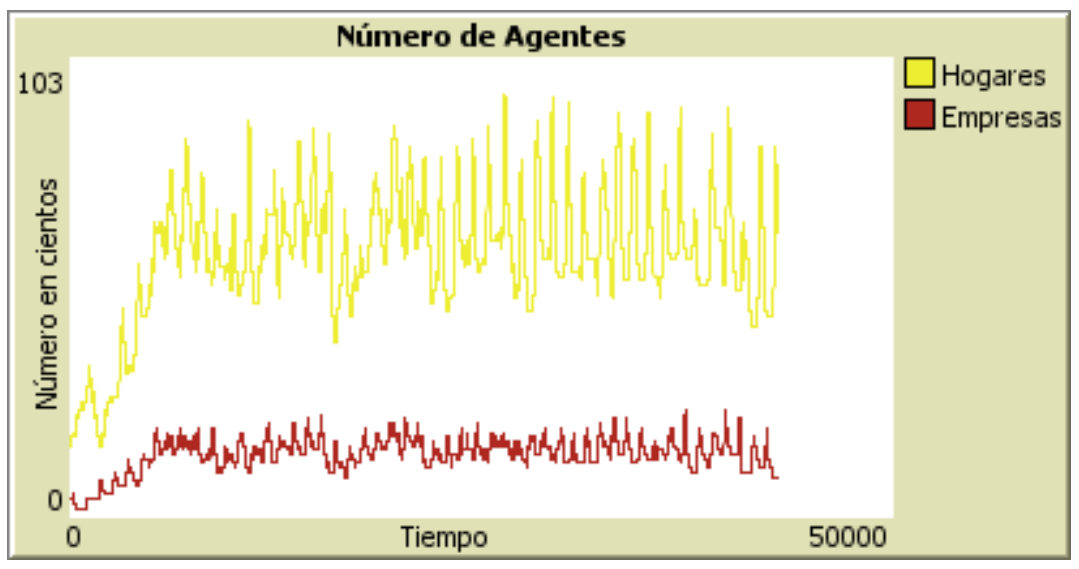

Figura 11. Número de hogares y de empresas luego de 50,000 iteraciones.

Los hogares se caracterizan porque algunos de sus miembros participan en la PEA (Población Económicamente Activa), y además por consumir. Para que las familias adquieran más poder adquisitivo en una sociedad, no sólo son importantes los aumentos de la productividad (a través de reforma agraria, y maquinaria moderna) y consecuentemente de la producción, la existencia de subsidios al sector primario, sino además que los sueldos y salarios sean elevados (Hicks, 1963) y que los impuestos al consumo sean bajos (Besley \& Rosen, 1998).

Respecto a las remuneraciones a los empleados, éstas dependen de la oferta y demanda por ciertos tipos de empleo (Akerlof \& Yellen, 1986); así, por ejemplo, si existe mucha demanda por un cierto grupo de profesionales, técnicos o especialistas, y la oferta de los mismos es limitada, los sueldos dispuestos a pagar las empresas serán elevados. Si la situación es inversa, los salarios de este grupo tenderán a ser bajos o habrá despidos. Las formas de elevar las remuneraciones son a través de la formación de sindicatos o imponiendo leyes que fijen salarios mínimos (Brown, 1999) de acuerdo a las diferentes actividades, profesiones y destrezas, debiéndose aclarar que el límite promedio a los mismos está fijado por el PIB per cápita de la población activa (Donoso Correa, 2000). Índice que se refiere al valor monetario que tocaría a cada empleado o subempleado si la riqueza estuviera perfectamente bien distribuida en un país o región, o también indica la productividad promedio de cada empleado o subempleado en la economía. Como la compensación a los empleados es sólo uno de los componentes del PIB según el ingreso (Landefeld et al., 2008), las otras variables son: excedente bruto de explotación, ingreso mixto bruto, impuestos que se añaden y subsidios que se sustraen en producción e importaciones. Lo aconsejable es que con fines de redistribución de la riqueza y de aumentar los niveles de consumo, este indicador sea mayor al 50\% del PIB (Stockhammer, 2013).

En muchos países, las empresas de los sectores primario (agricultura y ganadería) y terciario (servicios y comercio) tienden a pagar sueldos más bajos a sus empleados en relación a los ingresos percibidos por los obreros, técnicos y empleados administrativos del sector secundario (Krueger \& Summers, 1986). Sin embargo, del sector terciario se puede categorizar un subsector denominado sector cuaternario, el mismo que se caracteriza porque sus empleados obtienen remuneraciones más elevadas, debido a que se trata de un sector basado en el conocimiento (Kenessey, 1987), y que está formado por empresas que emplean a profesionales de todo tipo (médicos, odontólogos, abogados, etc.), centros de educación y universidades (profesores universitarios), compañías de software (ingenieros en sistemas), departamentos de investigación en empresas innovadoras (compañías farmacéuticas, de microprocesadores, aeronáutica, etc.), consultorías, instituciones gubernamentales dedicadas a la investigación, etc. Generalmente, mientras mayor es el porcentaje del sector cuaternario dentro de la economía de un país, más familias de clase media alta tienden a existir (Brint, 2001), aunque esto no sucede siempre en muchos países en vías de desarrollo o no se daba en los países ex socialistas; por otro lado, más investigación y avances tecnológicos se darán.

Si bien es cierto que dentro del sector cuaternario hay un grupo de profesionales de diferentes ramas dedicados a la investigación, esta actividad en muchas ocasiones necesita fuertes inversiones en 
infraestructura e instrumentos, como es el caso de la construcción de sincrotrones (Wiedemann, 2015). Los fondos provienen principalmente de los gobiernos y en menor medida del sector privado (Mazzucato, 2011). Además, cierto tipo de investigaciones científicas encaminadas al desarrollo de nuevas tecnologías demandan un elevado gasto corriente del sector público en sueldos (Goolsbee, 1998), y debido al alto riesgo de fracaso en investigaciones que no llevan a resultados concretos o productos comercializables a futuro, por ejemplo, en la industria farmacéutica (Schäfer \& Kolkhof, 2008). A todo esto, se deben sumar los problemas enormes al tratar de cambiar la pequeña escala y la baja productividad de las tecnologías empleadas en el laboratorio, a la gran escala y alta productividad de las plantas industriales (Markham, 2002). La recomendación en este caso para países pobres es que sus pocos recursos económicos (en base a deudas muchas veces) deben ser optimizados en inversiones principalmente de carácter productivo (industrialización) y no en inversiones de alto riesgo (investigación); es decir que, es preferible inicialmente ser consumidor de bienes de capital antes que tratar de construirlos internamente. A medida que el país va mejorando económicamente, podrá empezar a fabricar maquinarias y, solamente cuando la situación económica lo amerite, los gobiernos deben invertir en investigaciones costosas de alto riesgo.

Cuando los niveles de desempleo y subempleo en algunos países son demasiado elevados, los gobiernos podrían establecer, para empresas públicas y privadas de tamaño mediano o grande del sector secundario y terciario, en vez de sólo una jornada laboral diaria, dos o tres jornadas laborales con el fin de incrementar el empleo y la producción sin inversión adicional (Hunt \& Katz, 1998), utilizando la misma infraestructura o capacidad productiva existentes al interior de cada empresa. En el caso del sector primario, específicamente de las actividades agroganaderas, silvicultura y acuicultura, no tendría sentido incrementar el número de jornadas laborales, ya que pese a que los abonos o la alimentación incrementan la productividad (Hayami \& Ruttan, 1970), la producción en el tiempo depende de ciclos biológicos de las diferentes especies de plantas o animales, algo que no sucede con actividades extractivas como la minería o la pesca.

\subsection{Las empresas en los diferentes sectores de la economía y la importancia del manejo adecuado del sector primario}

Al analizar la distribución de las actividades económicas por sectores productivos en el modelo planteado (Figura 12), ésta nos muestra claramente que en las economías modernas urbanas prevalece el sector terciario (de comercio y servicios) sobre el sector secundario o industrial, mientras que el sector primario (agropecuario y minero) es mínimo, coincidiendo plenamente con las estadísticas del Banco Mundial (World Bank Group, 2012) y la Organización para la Cooperación y el Desarrollo Económico (OECD, 2013) en lo relacionado al porcentaje de cada sector económico respecto al PIB así como de la participación de la población económicamente activa en los diferentes sectores.

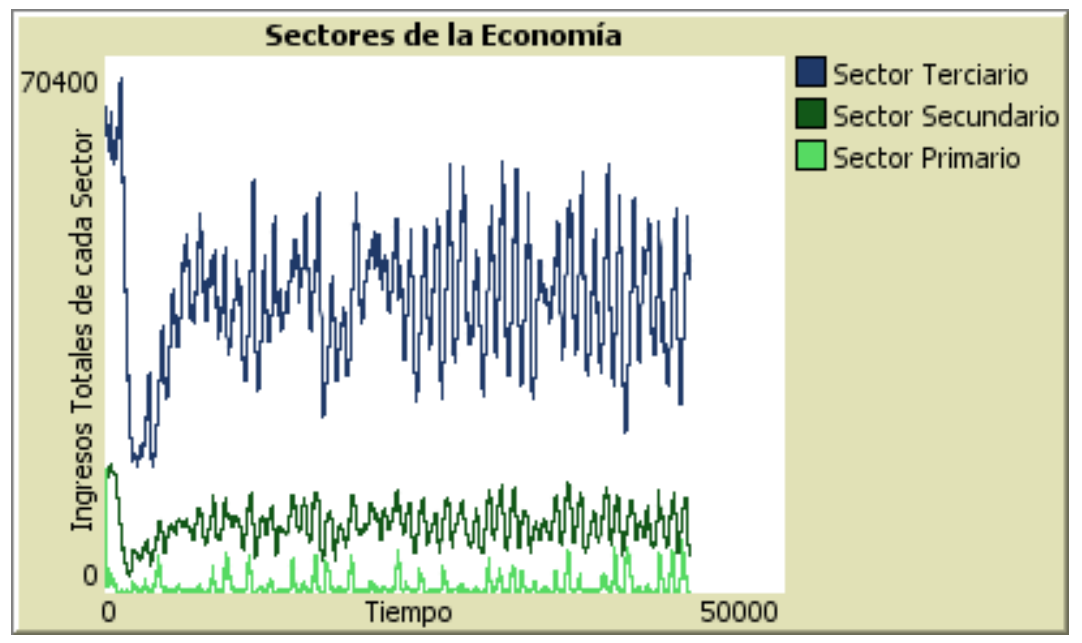

Figura 12. Ingresos totales de empresas en cada sector de la economía luego de 50,000 iteraciones. 
Si todos los bienes tienen su origen en el sector primario, es evidente que este sector tiene una importancia trascendental en la economía (Anderson et al., 2006). Esto ocurre en países desarrollados (Bale \& Lutz, 1981) como Estados Unidos, miembros de la Unión Europea (Rizov et al., 2013), Japón (Mulgan, 2013), Australia (Chisholm, 1992), y algunos en vías de desarrollo como China (Gale et al., 2005) y Brasil (Clover, 2003). Estos países mantienen diferentes tipos de subsidios a las empresas extractoras o explotadoras de recursos naturales, para así garantizar la seguridad alimentaria de su población, además de abaratar costos de materias primas en el origen de las cadenas de producción y distribución. Sin embargo, para los países más pobres del planeta, como son la mayoría de naciones del África Subsahariana (Clover, 2003) y Asia del Sur, se les vuelve imposible subsidiar al sector primario, ya que las actividades agrícolas constituyen un porcentaje demasiado elevado de sus PIB (World Bank Group, 2012), debido a que sus poblaciones todavía son mayoritariamente rurales (Angel, 2012) y se vuelve imposible utilizar los bajos montos de impuestos recaudados (Auriol \& Warlters, 2005) en sectores industriales débiles y sectores terciarios, caracterizados por el subempleo y la informalidad tanto en comercio como en servicios, para subsidiar a sectores primarios (caracterizados por minifundios, microfundios y baja productividad) que constituyen cerca del $50 \%$ o más en sus economías.

Se debe indicar que tanto los latifundios como los minifundios y microfundios constituyen graves problemas socioeconómicos, ya que las grandes haciendas generan una mala distribución de las tierras rurales (Griffin et al., 2002); mientras que la pequeña propiedad muchas veces corresponde a agricultura de subsistencia (Clark \& Haswell,1964), generando bajos niveles de ingresos y utilidades (Binswanger, Deininger \& Feder, 1993), que primordialmente se destinan a la supervivencia familiar. En muchas ocasiones hay ausencia de títulos de propiedad y el acceso a créditos es más difícil y generalmente muy limitado (Gilbert, 2002), por lo que existe baja re-inversión en insumos, tecnología e infraestructura. Aunque existe un grupo de autores (Bardhan, 1973; Berry \& Cline, 1979; Cornia, 1985; Ghose, 1979; Taslim, 1989) que manifiestan que, en algunos países en vías de desarrollo, mientras menor es el tamaño de la propiedad, existe una mayor productividad. Lo que sí es evidente es que, la mediana propiedad tiende a tener similar productividad (producción por hectárea) (Gardner, 2009) que las grandes Unidades de Producción Agropecuaria (UPAs), ya que en ambos casos, la productividad depende de ciclos biológicos de crecimiento de animales y de plantas, y tanto las medianas como las grandes UPAs, al tener más acceso a capital (ya sea por ingresos o créditos), pueden comprar mejores animales y semillas, alimentos y fertilizantes, productos farmacéuticos y químicos para contrarrestar enfermedades y plagas, comprar maquinaria u otras tecnologías agrícolas y construir infraestructura para su adecuado funcionamiento. En base a lo anotado anteriormente, se recomienda que se realicen reformas agrarias (expropiando e indemnizando a los grandes y pequeños propietarios) encaminadas a generar una estructura agraria en base a UPAs de mediana extensión por razones concernientes a justicia social y a mejorar la productividad. Obviamente, es necesario indicar que lo que se considera mediana propiedad dependerá no exclusivamente del tamaño de las parcelas de tierras rurales, sino más bien de las utilidades promedio que generan los diferentes cultivos o usos del suelo por hectárea; es así que por ejemplo una hectárea de rosas teóricamente podría generar utilidades similares a cinco hectáreas de banano o veinte y cinco hectáreas de ganado bovino. Se debe además crear leyes similares a las que se dieron en numerosos estados de India (Mearns, 1999) desde 1956 hasta 1986 (Land Reforms Acts) y Nepal (Regmi, 1976) (Land Act 1964) encaminadas a impedir la fragmentación (Niroula, \& Thapa, 2005), así como leyes similares a las que se dictaron en Japón (Hayami, 1988) (Land Law 1962) y Taiwán (Tai, 1974) (Land Act 1953) para evitar las graves consecuencias de una posterior unificación de parcelas.

Una adecuada reforma agraria es solo el inicio de lo que se debe hacer, es necesario además que los gobiernos ayuden al sector primario de las siguientes maneras: 1) generando líneas de créditos con bajas tasas activas de interés a largo plazo (Yaron, 1994) y subsidiando insumos, tecnologías, energía y transporte (Alston, 2007) para que los precios de mercado de alimentos y materias primas sean lo más bajos posibles; 2) otra alternativa para lograr esta meta es la fijación por parte de los gobiernos de precios mínimos referenciales que los intermediarios o industriales deben pagar por los bienes provenientes del sector agro-ganadero y minero, tal y como sucede con productos de exportación como el banano en muchos países del mundo (Donoso Correa, 1996), garantizando así utilidades suficientes para los accionistas de las empresas o familias, y la existencia de capitales para re-invertir en tecnologías 
que aumenten la productividad. Obviamente, estos precios más elevados afectarán a las industrias y hogares que consumen estos productos, razón por la cual el gobierno debe subsidiar a los consumidores (comerciantes, industrias y hogares) de bienes del sector primario (Schwartz \& Clements, 1999). Cualquiera de las dos alternativas, generará seguridad alimentaria en los países que decidan implementar estas políticas, además de aumentar la productividad y de disminuir los precios al inicio de las cadenas de producción y distribución, lo que se transforma en mayor poder adquisitivo para los consumidores. Respecto a los productos importados, si estos son subsidiados por otro país (dependerá del porcentaje en el precio de los subsidios), quizá sea conveniente para una nación pobre aprovechar la alta productividad y el bajo precio de estos bienes y permitir su importación sin aranceles.

En definitiva, es ventajoso para una economía que existan tasas de interés activas bajas, alta productividad y subsidios a los factores de la producción y al transporte (en color amarillo, ver Figura 13), prioritariamente al inicio de las cadenas de producción y de distribución, es decir a las empresas del sector primario. La alta productividad acompañada de subsidios ayuda a disminuir los costos de los procesos productivos, mientras que la competencia (cuando hay muchos oferentes) disminuye los márgenes de utilidad (Blattberg \& Wisniewski, 1989). Por otro lado, es importante que los trabajadores o empleados sean bien remunerados (en color azul), para de esta manera incrementar al máximo el poder adquisitivo de las familias (Carroll \& Summers, 1991).

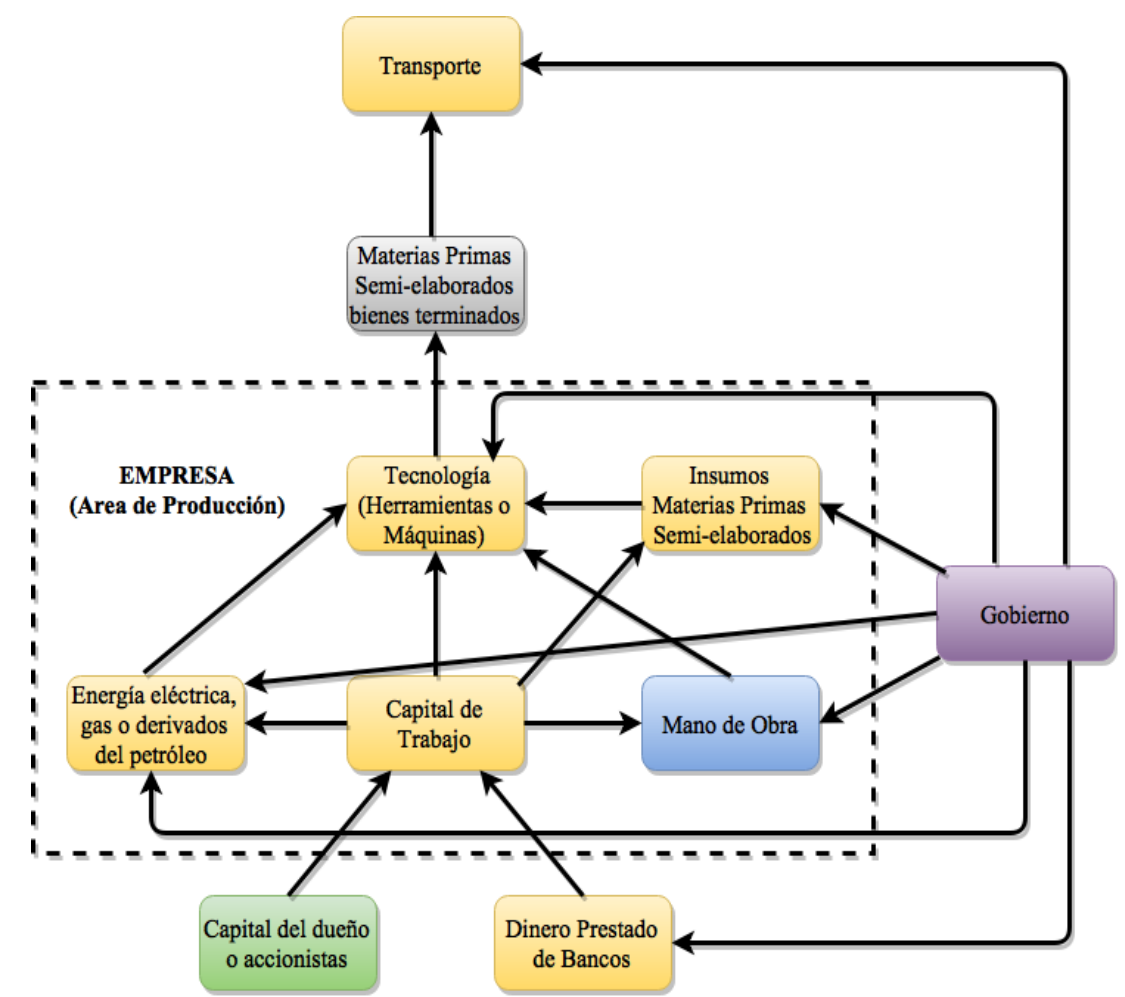

Figura 13: Importancia de los subsidios al sector primario.

Por otro lado, y dentro del manejo estratégico del sector primario, si un país posee reservas de petróleo o gas natural, sería conveniente que su explotación sea a través de una empresa pública, pues las ingentes utilidades pueden utilizarse para que los gobiernos las distribuyan en forma de inversión productiva o subsidios (totales o parciales) a la salud, educación, etc. (Ross, 2012), aunque lamentablemente a veces hay corrupción. Varios países miembros y no miembros de la Organización de Países Exportadores de Petróleo (OPEP) decidieron nacionalizar estos recursos naturales, siendo México 1938 (Woolsey, 1938) e Irán (1951) los pioneros, mientras que muchos otros países siguieron estas políticas una o dos décadas después (Kobrin, 1985). Así se evita, que el dinero generado por la venta de hidrocarburos vaya a las manos de un grupo reducido y elitista de millonarios en la sociedad, los mismos que contribuyen solo de manera parcial al Estado, a través de impuestos que corresponden 
a un porcentaje de las utilidades brutas, tal como sucedió en los Estados Unidos a fines del Siglo XIX, naciendo así entre muchos afortunados, el imperio Rockefeller (Nevins \& Rockefeller, 1940).

\subsection{Los tamaños originales de las empresas son claves para su dinamismo futuro, donde lo más importante es la productividad}

Otro gráfico interesante (Figura 14) demuestra el ingreso promedio de las empresas de acuerdo a cuatro tamaños: transnacionales, grandes, medianas y pequeñas. Es interesante que, pese a que hay variabilidad en el tiempo, el tamaño con el cual se fundan las empresas (Figura 15) constituye un indicador fundamental para su dinámica futura, ya que la mayoría de estas mantienen su tamaño en el tiempo, mientras que algunas disminuyen de tamaño o desaparecen y muy pocas logran expandirse, razón por la cual el microcrédito a tasas moderadas de interés quizás constituye una ayuda a las familias más pobres y pequeños negocios, haciéndolos crecer inicialmente para que poco tiempo después muchos de ellos sólo decrezcan debido al endeudamiento (Ahlin \& Jiang, 2008/4; Khan, 2009; Roth, 1997). Obviamente esta política no puede ser la solución para alcanzar adecuados niveles de desarrollo económico.

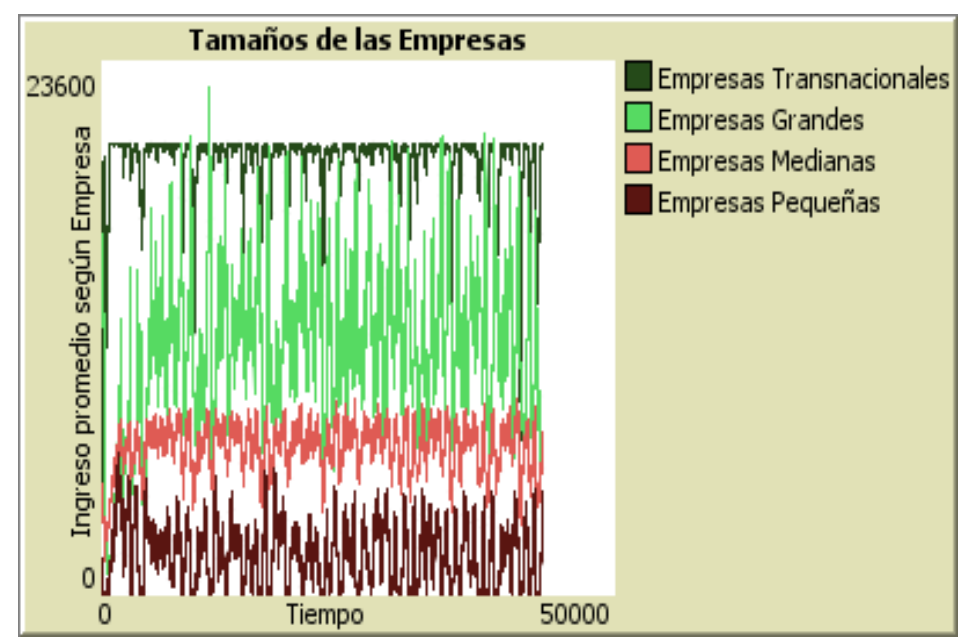

Figura 14. Ingreso promedio según tipo de empresa en cada sector de la economía luego de 50,000 iteraciones.

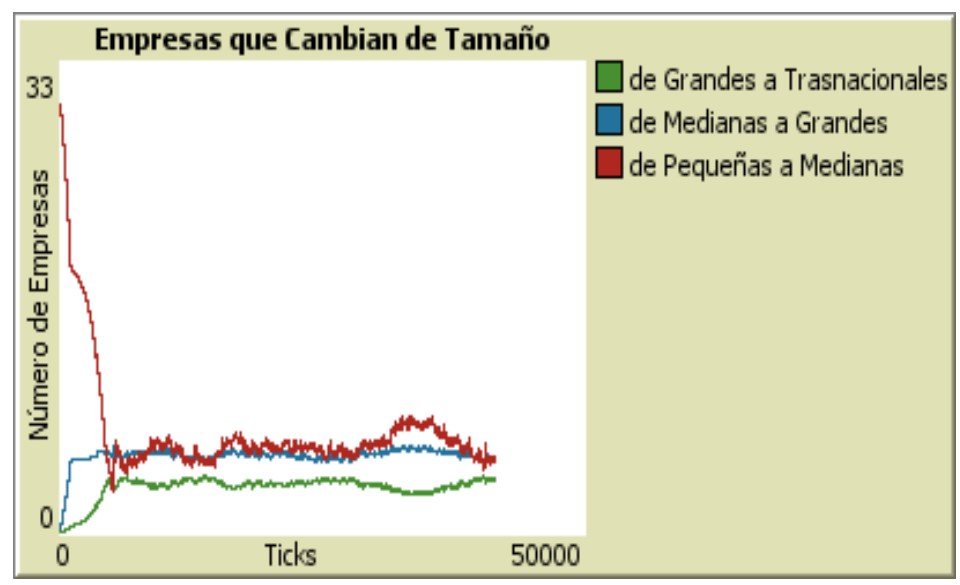

Figura 15: Número de empresas que cambian de tamaño en cada iteración de tiempo $(50,000$ iteraciones).

La alta productividad en el sector industrial depende principalmente de las maquinarias existentes (Salter, 1966), aunque también se debe considerar la capacitación y la salud de los empleados, así como también la organización y la cooperación existente en el trabajo. No es igual producir un bien sólo en base a herramientas, que confeccionarlo con máquinas de mediana productividad o realizarlo con 
tecnología de "punta". La tecnología influye no solamente generando más producción, sino sobre todo aumentando muchos indicadores de productividad (cantidad de productos por hora, cantidad de productos por obrero, cantidad de productos por consumo energético, etc.). Obviamente, la inversión de capital variará enormemente, siendo las grandes empresas aquellas que pueden adquirir (por tener más dinero o más capacidad de endeudamiento) las máquinas más sofisticadas y con mayor productividad. El aumento en la productividad (principalmente la cantidad de productos por hora) tiene una injerencia fundamental en la disminución de costos de producción de materias primas y de bienes semielaborados o terminados. Obviamente, el volumen de ventas (demanda por bienes) es importante, ya que de éste depende que las máquinas trabajen a niveles cercanos al $100 \%$ de la capacidad instalada (disminuyendo los costos de producción) o a porcentajes menores (generando costos más altos). Por otro lado, la competencia reduce el margen de utilidades de las empresas, generando consigo precios de mercado más bajos y aumentando por ende el poder adquisitivo de las personas. Algo más que se debe destacar en el sector secundario son los encadenamientos industriales, los mismos que ayudan a generar más diversidad y complejidad en la producción, y por ende más empleo en el sector productivo. Por ejemplo, si existen dos países: A y B, el primero es un importador de automóviles, mientras que el segundo país decide extraer las materias primas y fabricar los productos semielaborados y los bienes finales. En esta hipótesis, el país A generará empleo exclusivamente en el sector de importación y ventas de automóviles, mientras el país B creará empleo a lo largo de las cadenas de producción y de distribución; extrayendo petróleo, magnetita, bauxita y cuprita en el sector minera, y en plantaciones de caucho, luego más trabajo en la industria petroquímica, siderúrgica, metalúrgica y del caucho, después más empleo en industrias de tableros, volantes, carrocerías, motores, aros, alambres, llantas y mangueras, para luego generar más puestos de trabajo en la industria del ensamblaje de automóviles y finalmente en el sector de ventas.

Algo más que disminuye el precio final de venta de los bienes, es que estos se mueven a través de las cadenas de distribución con el menor número de intermediarios (Coughlan \& Lal, 1992), ya que cada uno de estos reclama su utilidad correspondiente. Por último, la variación existente en los impuestos al consumo o ventas que adoptan los diferentes estados sobre los diferentes productos y servicios hacen que los precios finales de éstos varíen de país a país (Tait, 1988). Así, por ejemplo, mientras Dinamarca tiene un impuesto del $25 \%$ al valor agregado (VAT) en muchos bienes, y otros países nórdicos tienen impuestos similarmente elevados a las ventas (Bird \& Gendron, 2007); en cambio, naciones como Qatar, Omán y Emiratos Árabes Unidos no tienen este tipo de impuesto (VAT $=0 \%$ ). En lo relacionado a bienes importados, también altos aranceles generan precios finales mayores de productos extranjeros, mientras que, si estos se mantienen bajos, los bienes provenientes de otros países serán menores.

Los impuestos que se añaden a los productos y que pagan los consumidores, como el impuesto al valor agregado o a consumos especiales, incrementan el precio final de venta (Besley \& Rosen, 1998); de la misma manera que los subsidios a los consumidores disminuyen el precio de mercado de los bienes y servicios. Por otra parte, es importante no fijar aranceles a los bienes de capital, alimentos o materias primas que no se producen ni se podrán producir en el país.

Si las industrias de un determinado país no están en condiciones de competir con las grandes transnacionales, no se debe permitir el libre comercio internacional (List \& Colwell, 1856), más bien se deben implementar aranceles como medidas proteccionistas al sector primario e industrial (Baer, 1972), ya que, de otra forma, la agricultura y las industrias de las naciones tecnológicamente más avanzadas fácilmente pueden destruir la naciente producción primaria y manufacturera de un país más pobre y de menor productividad.

En el sector terciario, es más difícil que la productividad de muchos servicios aumente y por ende los precios de mercado disminuyan, ya que ésta depende del conocimiento y la técnica empleada por personas que trabajan con herramientas. Por ejemplo, si hace cincuenta años un médico se demoraba en auscultar a un paciente veinte y cinco minutos, hoy se demora el mismo tiempo pese a que sus herramientas han cambiado de termómetros, estetoscopios y tensiómetros simples a digitales (Barzel, 1969). De igual manera, un cirujano que se demoraba dos horas en operar a un enfermo de apendicitis, en la actualidad se demora un tiempo similar, pese a que su instrumental ha cambiado del bisturí simple al robot Da Vinci Surgical System (Ballantyne \& Moll, 2003) y la técnica de cirugía laparotómica a laparoscópica. Similarmente, un profesor universitario daba su clase en una hora a sus estudiantes hace 
medio siglo, mientras que hoy se demora el mismo tiempo, pese a que, en vez de utilizar pizarra y tiza, estas herramientas han cambiado a computadora y proyector (Long, 1952). Cuando los servicios incluyen componer o reemplazar bienes, el trabajo humano es bien remunerado (países más desarrollados) y los bienes a ser arreglados o reemplazados se producen más eficientemente que antes y por ende han bajado de precios, ha existido una evolución en la forma como se ofertan estos servicios. Por ejemplo, en vez de reparar un motor de automóvil desarmándolo, reemplazando pieza por pieza y luego armándolo nuevamente, simplemente se cambia con un motor nuevo y de esta manera se ha dado un aumento en la productividad en la oferta del servicio de mecánica automotriz. Lo mismo sucede en una latonería, antes se arreglaba la puerta de un carro averiado utilizando varias horas de mano de obra y ahora simplemente se la reemplaza con una puerta nueva en pocos minutos, ahorrándose costosa mano de obra. Otros servicios donde han existido aumentos en la productividad han sido aquellos que emplean el internet, como por ejemplo los cursos académicos donde un profesor puede enseñar a través de una aula virtual, no únicamente a veinte o treinta alumnos (como en una aula física), sino a miles de alumnos simultáneamente como sucede con la página web Coursera (Ruiz Martín, 2013); o si un técnico arregla los problemas relacionados con el software de una computadora a través del internet en vez de desplazarse físicamente al lugar donde se encuentra la máquina, existiendo ahorro en transporte así como incremento en la productividad al obviar el tiempo de desplazamiento.

Por otro lado, existen profesiones y actividades donde parcialmente a mejorado la productividad gracias a la introducción de mejores herramientas de trabajo, es así que un abogado antes se demoraba media hora en redactar una carta en una máquina de escribir, mientras ahora lo realiza en menos minutos con la utilización de templetes y programas de procesamiento de palabras tipo Word (Camarda, 2001) o Google Docs (Dekeyser \& Watson, 2006). Sin embargo, éstas no son las únicas tareas que son responsabilidad de los abogados, ya que deben además de representar a sus clientes en las Cortes de Justicia, deben escucharlos y aconsejarlos. Algo similar ha ocurrido con los contadores, que antes llevaban los asientos contables manualmente y tenían que establecer los estados de situación final y de pérdidas y ganancias con calculadora, mientras hoy lo hacen con software especializado y automatizado (Banker et al., 2002). Existiendo un ahorro enorme de tiempo y por ende mayor productividad profesional. Otro ejemplo de abaratamiento de costos gracias a las mejoras de la productividad se da en los restaurantes de comida rápida (Doutt, 1984), donde detrás de los mismos existen industrias alimenticias que preparan los menús para ser únicamente cocidos en pocos minutos antes de ser servidos, así se abarata costos y los precios de mercado son menores. En el caso del comercio de mercaderías, ha habido incrementos en la productividad y disminución de empleados sobre todo en lo relacionado con la eficiencia al momento de comprar algún bien mediante páginas web (Lohse \& Spiller, 1998), así como en el despacho de las mismos, a través de robots como es el caso de grandes empresas (Wurman et al., 2008), por ejemplo, Amazon.

\subsection{La banca pública como motor dinamizador del desarrollo económico}

El capital de trabajo que destinan los individuos y empresas a sus negocios, así como las tasas activas de interés (préstamos de bancos a personas y empresas) son los dinamizadores del sector privado de la economía. Estos intereses dependen de los siguientes factores:

1) oferta y demanda de dinero en el sistema que fijan el precio (interés) del mismo, es aquí donde los gobiernos juegan un papel fundamental controlando la política monetaria (Klein, 2000), ya sea de manera expansiva o contractiva;

2) nivel inflacionario (Mundell, 1963), ya que la tasa de interés activa siempre tiende a estar por encima del mismo (pese a que las tasas pasivas de interés muchas veces están por debajo de la inflación), ya que caso contrario causaría pérdidas de poder adquisitivo a los bancos;

3) encaje bancario (Demirgüç-Kunt \& Huizinga, 1999), mientras más elevado es este porcentaje, más alta tiende a ser la tasa de activa de interés, debido a que de cada depósito queda un porcentaje menor para destinarse como préstamo;

4) tasas pasivas (Ho \& Saunders, 1981), las cuales determinan el porcentaje de interés al cual se capta el dinero y además constituyen, conjuntamente con las tasas activas, la brecha que da como resultado los márgenes de utilidad bruta de las entidades crediticias, debiéndose aclarar 
que los bancos privados compiten primero por captar el dinero (y esto genera presión hacia tasas pasivas de interés más elevadas) y luego por prestar;

5) leyes emanadas por los gobiernos que impiden prestar por encima de ciertas tasas de interés (Glaeser \& Scheinkman, 1998);

6) riesgo de la inversiones, garantías otorgadas y montos de préstamos, ya que los bancos valoran el riesgo de ciertas actividades, asegurándose consecuentemente con hipotecas, prendas, pagarés, cheques o a través de firmas de garantes (Edwards, 1984), también implementan distintas tasas de interés activas de acuerdo a la cantidad de dinero que prestan (generalmente a mayor monto, menor es la tasa).

Se debe aclarar que en casos de ciertas divisas que se devalúan por encima de los niveles inflacionarios nacionales en relación a monedas "fuertes" como el dólar o el euro, los bancos de esos países tienden a tener tasas activas de interés por encima de los niveles de devaluación monetaria (Edwards, 1984), para no perder dinero cuando se transforma a otra divisa "fuerte".

La tasa de inflación, el encaje bancario y las leyes que prohíben préstamos de las entidades financieras por encima de ciertos porcentajes dependen del gobierno; es así que la inflación (Hall, 2009) (cuando no es inflación causada por un incremento en la demanda) se genera por desajustes entre la cantidad de bienes y servicios en relación a la masa monetaria total existente en el mercado (ecuación mencionada anteriormente sobre la teoría cuantitativa del dinero). Esta situación resulta en inflación si existe más oferta de dinero en relación a la producción, y deflación en el caso contrario. Pese a que lo óptimo es tener un nivel inflacionario de cero (0\%), los gobiernos tienden a generar niveles inflacionarios bajos para así reducir o evitar déficits fiscales (Piketty et al., 2014). El encaje bancario cumple un propósito doble: disminuye el efecto multiplicador del dinero en el sector financiero, y a la vez crea un margen de seguridad en los depósitos (Walters, 1967). Es por ello que, a mayor encaje bancario, más se frena el efecto multiplicador del dinero y más seguridad en los depósitos existe, pero menos porcentaje del dinero captado se destina a préstamos y por ende las tasas activas de interés tienden a ascender, en tanto que, si el encaje bancario por ley es menor, el efecto contrario sucede. Para dinamizar la economía de una manera óptima, proporcionando a individuos y empresas préstamos a bajo interés o "baratos", es fundamental tener porcentajes de inflación reducidos, encajes bancarios no tan elevados, márgenes de utilidades bancarias reducidos y leyes que impidan altas tasas activas de interés.

Una banca pública (Brown, 2013) bien manejada indudablemente proporciona ventajas comparativas frente al sector financiero privado; ya que podría arriesgar menos optando por préstamos productivos en vez de invertir en mercados bursátiles atractivos aunque de alto riesgo (Brown, 2008b); puede cumplir el rol de excluir menos personas y empresas, proporcionar tasas activas de interés más bajas al no tener que competir por captar dinero elevando las tasas pasivas de interés; y a las vez que puede mantener utilidades más moderadas que el sector privado. De hecho, el progreso económico de China en las últimas décadas no se debe únicamente a las políticas nacionales de industrialización, sino además al sistema de banca estatal (Wei \& Wang, 1997) con su Banco Central, sus cuatro grandes bancos estatales (Banco de China, Banco de la Construcción, Banco Industrial y Comercial y Banco Agrícola) y una multitud de bancos locales manejados por los gobiernos de sus ciudades (Cousin, 2011), tales como el Banco de Beijing o el Banco de Ningbo.

\subsection{Análisis final: el PIB de acuerdo al gasto}

Si se observa la conformación del PIB de acuerdo al gasto (Landefeld et al., 2008), este corresponde a la suma del consumo de los hogares $(C)$ más el consumo del Gobierno $(G)$, más la inversión $(I)$, más las exportaciones $(X)$ y menos las importaciones $(M)$. Su fórmula se representa así: $P I B=C+G+I+$ $(X-M)$. La recomendación en este caso es que reconociendo la importancia que tiene el sector público en la generación de empleo y en otorgar servicios (educación, salud, etc.) y subsidios, demasiado gasto público $(\mathrm{G})$ implica necesariamente una disminución del consumo privado $(C)$ vía impuestos (Widmaier et al., 1972). Por ende, el gasto corriente en sueldos dentro del sector público debe ser optimizado, ya que es un sector dependiente de impuestos recaudados en el sector productivo privado. Gobiernos donde el número de empleados es reducido en sus instituciones públicas, tienden a ser más eficientes y demandan menos impuestos (Ott, 2006). 
Obviamente, al analizar la relación entre exportaciones $(X)$ e importaciones $(M)$, siempre es más conveniente captar dinero de otros países a través de ventas al exterior antes que enviar recursos económicos importando bienes (Krueger, 1980). Además, mientras más exporta un país y menos importa, su nivel de dependencia del resto del mundo disminuye. Con la finalidad de reducir costos de producción, se necesitan políticas arancelarias y de cuotas encaminadas a sustituir importaciones por industrialización (Lin, 1973), con la exoneración de bienes de capital que no se produzcan internamente e insumos.

Otro componente que es de vital importancia en esta ecuación es la inversión (I), la misma que es de carácter pública y privada. Mientras más elevado es su porcentaje en relación a los otros componentes de la ecuación, ésta tenderá a incrementar el PIB a futuro (Morgan, 1969). La recomendación en este caso es que el gobierno incremente al máximo la inversión pública, disminuyendo el gasto corriente (Devarajan et al., 1996). Pero, la inversión pública no debe estar destinada únicamente a construir centros educativos, hospitales, vialidad, viviendas populares, etc., sino a priorizar sobre todo la construcción de grandes industrias con tecnología de punta, caracterizadas por su alta productividad y producción, para así disminuir los costos de fabricación de los bienes (Baily et al., 1992). Por otro lado, los gobiernos no deben crear únicamente una gran fábrica para producir un determinado bien, sino varias de éstas para así generar competencia, disminuyendo de esta manera los márgenes de utilidad (Porter, 2008). Finalmente es importante que exista distribución de la riqueza, pero no exclusivamente de los ingresos vía impuestos y luego a través de subsidios, sino del patrimonio mismo, privatizando las industrias creadas por el gobierno a través de la venta de paquetes accionarios, donde se establezcan límites máximos de compras de acciones por individuo. De este modo, no serán exclusivamente las personas con más recursos económicos aquellas que adquieran las compañías, sino se favorecerá una participación de todo tipo de personas; los ricos comprarían acciones con dinero en efectivo, individuos de clase media se financiarána través de bancos privados o públicos y en el caso de las personas de bajos recursos, a través de créditos otorgados por bancos públicos con tasas activas de interés preferenciales y a largo plazo. La venta de estas empresas públicas deberá además tener un margen de ganancia moderada con respecto a la inversión en la creación de las mismas. Esto, a diferencia de lo que sucede en los mercados bursátiles tradicionales, en los mismos que las acciones están sobrevaloradas en relación al patrimonio real que representan (Shiller, 2015), apareciendo multimillonarios y creándose burbujas especulativas (Scheinkman \& Xiong, 2003) que cuando hay estrés o recesiones económicas tienden a desinflarse con facilidad.

La razón fundamental por la cual deben ser los gobiernos los que creen estas industrias es simplemente porque los actores económicos del sector privado tienen un poder limitado de asociación (con excepción de unas pocas cooperativas como Mondragón o cuando algunas empresas han crecido y venden acciones) y de inversión (con excepción de personas o familias económicamente muy solventes). Estas incapacidades se observan tanto en países desarrollados como en los subdesarrollados, donde la mayoría de empresas son pequeñas, existiendo un porcentaje más bajo de empresas medianas, algunas empresas grandes, y pocas que llegan a ser transaccionales (Axtell, 2001). Por ende, es un error pensar que debe ser la inversión privada exclusivamente el motor generador del desarrollo económico, ya que en la realidad los empresarios se demoran demasiado tiempo en competir en el mercado para que unos pocos lleguen a ser medianos y, de éstos aún menos se harán grandes con el paso de muchos años, lo que implica que la sustitución de sus máquinas por tecnologías innovadoras de alta productividad (Swamidass \& Kotha, 1998) es un proceso lento. Un ejemplo interesante de lo que se debe hacer para mejorar la productividad y disminuir el costo de producción se lo puede apreciar en la súper fábrica creada por Tesla Motors y Panasonic en Nevada, que a través de una alta inversión en tecnología de avanzada será capaz de producir más baterías de iones de litio que todas las industrias del mundo juntas dedicadas a hacer estas fuentes de poder, pretendiendo así disminuir los costos de producción para finalmente fabricar vehículos eléctricos más asequibles en el mercado.

Por otro lado, la inversión estatal en industrias y luego su privatización (distribución de patrimonio) propiciará que el dinero invertido se recupere con el pasar del tiempo, a diferencia de lo que sucede cuando la inversión pública se efectúa en infraestructura de hospitales y centros de salud, instituciones educativas, vialidad (siempre y cuando las carreteras no tengan peajes) o peor aún en la adquisición de armamento bélico. En estos casos no existirá recuperación del capital invertido para el Estado (Aschauer, 1989), sino simplemente un dinamismo económico de corto tiempo (en el caso del 
armamento, siempre y cuando provenga de industrias nacionales). $\mathrm{Y}$ si estas infraestructuras $\mathrm{o}$ adquisición de tecnologías (Formación Bruta de Capital Fijo o FBCF) se realizaron con deuda, incluso puede generarse problemas a futuro en el pago de las mismas por parte de los gobiernos. Obviamente, muchos Estados han adquirido el compromiso de garantizar la salud y la educación de sus ciudadanos, y por ende es correcto y bien justificado cumplir con estos compromisos.

Con respecto a la carencia de productividad o a la industrialización de baja productividad, dos anécdotas históricas son importantes:

1) En el año 1349, a raíz de la alta mortalidad producida por la peste bubónica, hubo incrementos salariales, a tal punto que el Rey Eduardo III promulgó el Estatuto de los Trabajadores (Poos, 1983) para poner un límite a estos aumentos, que además generaban problemas de circulante basado en monedas metálicas acuñadas. Estos mayores ingresos generaron una mejor distribución de la riqueza, pero la gente seguía siendo pobre, porque sin innovaciones tecnológicas y con métodos de producción basados en herramientas, simplemente no hubo incrementos en la productividad.

2) El sistema socialista introducido en la Unión Soviética y otros países del mundo, jamás logró generar clase media porque las industrias jamás tuvieron tecnología de punta (Berliner, 1978), estaban sobre burocratizadas con el fin de mantener bajos niveles de desempleo (Porket, 1989), no había competencia entre ellas y finalmente, en vez de existir distribución de la riqueza, esta se concentraba en patrimonio Estatal (Piketty et al., 2014).

En contraste con estas historias, los hogares de Estados Unidos, un país con una distribución desigual de la riqueza de acuerdo al coeficiente de Gini (Atkinson, 2003), tienen el mayor ingreso disponible medido según la paridad del poder adquisitivo en relación a los otros países miembros de la Organización para la Cooperación y el Desarrollo Económico (OECD, 2016), y la respuesta, al menos parcialmente radica en sus altos niveles de producción y productividad, al tener grandes empresas muy tecnificadas en su sector primario y secundario.

\section{CONCLUSIONES}

Desde la visión macro, a través de diagramas de flujos se demostró el funcionamiento de cualquier sistema económico. Luego, mediante el uso de multi agentes encapsulados dentro de autómatas celulares se elaboró una demostración de cómo las empresas se comportan de acuerdo a sus tamaños y sectores de la producción, pudiéndose apreciar que el tamaño inicial de las compañías es un indicador fundamental de su desenvolvimiento futuro, ya que la mayoría de éstas mantienen sus ingresos en el tiempo, mientras que algunas desaparecen, y unas pocas tienden a crecer hacia el siguiente nivel jerárquico. Finalmente, se generan recomendaciones heterodoxas de cambios que se deben realizar en las políticas económicas en los diferentes países.

Específicamente, estas propuestas macroeconómicas colocan al gobierno como eje central de la inversión pública productiva, el mismo que a través de subsidios al sector primario disminuye los costos en el origen mismo de las cadenas de producción y de distribución, intentando además, con la generación de industrias a gran escala, aumentar la productividad (y por ende disminuir costos de producción), la competencia interempresarial (y así reducir los márgenes de utilidad), mientras que la economía se vuelve más compleja (por encadenamientos industriales), generándose más diversidad en la producción y además un mayor poder adquisitivo para las personas. Al mismo tiempo que aumentan los niveles de empleo y además propician una distribución de la riqueza no únicamente basada en los ingresos, sino en el patrimonio mismo a través de venta de acciones de empresas públicas con cupos limitados a los ciudadanos.

Existen otras propuestas interesantes que no se incluyeron en este artículo, relacionadas con la recaudación tributaria por parte de los gobiernos, específicamente a través de impuestos progresivos al valor agregado que los individuos deberían pagar de acuerdo al tamaño de la empresa donde compran, para así generar una competencia más leal entre compañías grandes y pequeñas; mientras que el impuesto a la renta (también progresivo) debería fijarse sobre los ingresos brutos de las empresas 
(obviamente en porcentajes más bajos), en vez de únicamente sobre las utilidades brutas. Otra idea que no se incluyó en este estudio es el fortalecimiento de las instituciones de control, propuesta encaminada a disminuir o evitar la evasión tributaria y la corrupción.

Como todas las proposiciones novedosas, y tal como sucedió cuando se formularon las primeras leyes de salario mínimo en Australia y Nueva Zelanda en 1890, o cuando se empezó a establecer el modelo Keynesiano de desarrollo económico a finales de los años 1930s, inicialmente siempre hay opositores o dudas, y la puesta en práctica de cualquier política depende exclusivamente de la voluntad de los gobernantes de turno (poder ejecutivo y legislativo) en un país. Además, para que un plan funcione, se necesitan décadas y décadas de aplicación continua.

Finalmente, se esperaría a futuro, que modelos más robustos en supercomputadoras puedan simular mejor el comportamiento macroeconómico de sociedades virtuales, cada vez con menos limitaciones, aunque siempre será el ingenio humano el que conduzca a la búsqueda de políticas novedosas, las mismas que se podrán probar una y otra vez cambiando las reglas del juego ortodoxas en estos modelos experimentales.

\section{BIBLIOGRAFÍA}

Ahlin, C., N. Jiang, 2008/4. Can micro-credit bring development? Journal of Development Economics, 86(1), 1-21.

Ahmed, S., M. Krumpelt, 2001. Hydrogen from hydrocarbon fuels for fuel cells. International Journal of Hydrogen Energy, 26(4), 291-301.

Akerlof, G.A., J.L. Yellen, 1986. Efficiency wage models of the labor market. Cambridge, UK: Cambridge University Press.

Allen, R.G.D., 1980. Balance of payments. An introduction to national accounts statistics: Balance of payments (Chapter), Springer Verlag, pp. 56-68.

Alston, J.M., 2007. Benefits and beneficiaries from US farm subsidies. AEI briefs: Agricultural Policy Series, $65 \mathrm{pp}$.

Amin, S.M., B.F. Wollenberg, 2005. Toward a smart grid: power delivery for the 21 st century. Power and Energy Magazine, IEEE, 3(5), 34-41.

Anderson, K., W. Martin, E. Valenzuela, 2006. The relative importance of global agricultural subsidies and market access. World Trade Review, 5(3), 357.

Angel, S., 2012. Planet of cities. Cambridge, MA: Lincoln Institute of Land Policy.

Armstead, H.C.H., 1978. Geothermal energy: its past, present and future contributions to the energy needs of man. Sydney, Australia: Halstead Press.

Argent, N., 2007. Neoliberalism: a critical reader. In: Saad-Filho, A., D. Johnston (Eds.). Geographical Research, 45(1), 105-106.

Aschauer, D.A., 1989. Is public expenditure productive? Journal of Monetary Economics, 23(2), 177-200.

Atkinson, A.B., 2003. Income inequality in OECD countries: Data and explanations. CESifo Economic Studies, 49(4), 479-513.

Auriol, E., M. Warlters, 2005. Taxation base in developing countries. Journal of Public Economics, 89(4), 625-646.

Auty, R.M., 2001. The political economy of resource-driven growth. European Economic Review, 45(4), 839-846.

Axtell, R.L., 2001. Zipf distribution of US firm sizes. Science, 293(5536), 1818-1820.

Baer, W., 1972. Import substitution and industrialization in Latin America: Experiences and interpretations. Latin American Research Review, 7(1), 95-122. 
Baily, M.N., C. Hulten, D. Campbell, T. Bresnahan, R.E. Caves, 1992. Productivity dynamics in manufacturing plants. Brookings Papers on Economic Activity. Microeconomics, 187-267. Available at https://www.brookings.edu/wp-content/uploads/1992/01/1992_bpeamicro_baily.pdf.

Bale, M.D., E. Lutz, 1981. Price distortions in agriculture and their effects: An international comparison. American Journal of Agricultural Economics, 63(1), 8-22.

Ballantyne, G.H., F. Moll, 2003. The da Vinci telerobotic surgical system: the virtual operative field and telepresence surgery. Surgical Clinics of North America, 83(6), 1293-1304.

Baloglou, C.P., 2012. Antoine Augustin Cournot. Handbook of the History of Economic Thought. The European Heritage in Economics and the Social Sciences, Vol. 11, pp. 437-463.

Banker, R.D., H. Chang, Y. Kao, 2002. Impact of information technology on public accounting firm productivity. Journal of Information Systems, 16(2), 209-222.

Bardhan, P.K., 1973. On the incidence of poverty in rural India of the sixties. Economic and Political Weekly, 245-254.

Barth, J.R., R. Dan Brumbaugh, J.A. Wilcox, 2000. Policy Watch: The repeal of Glass-Steagall and the advent of broad banking. The Journal of Economic Perspectives: A Journal of the American Economic Association, 14(2), 191-204.

Barzel, Y., 1969. Productivity and the price of medical services. Journal of Political Economy, 77(6), 1014-1027.

Basu, N., R. Pryor, T. Quint, 1998. ASPEN: A microsimulation model of the economy. Computational Economics, 12(3), 223-241.

Bhat, C., J. Guo, S. Srinivasan, A. Sivakumar, 2004. Comprehensive econometric micro-simulator for daily activity-travel patterns. Transportation Research Record: Journal of the Transportation Research Board, 57-66. Available at http://www.caee.utexas.edu/prof/bhat/ ABSTRACTS/CEMDAP_revised3.pdf.

Benenson, I., P.M. Torrens, 2004. Geosimulation: object-based modeling of urban phenomena. Computers, Environment and Urban Systems, 28(1), 1-8.

Bergenti, F., A. Poggi, 2000. Exploiting UML in the design of multi-agent systems. Chapter: Engineering Societies in the Agents World. Vol. 1972 of the series Lecture Notes in Computer Science, Springer Berlin Heidelberg, pp. 106-113.

Berentsen, A., 2005. Digital money, liquidity, and monetary policy. Available at http://firstmonday.org/ojs/index.php/fm/article/view/1512.

Berliner, J.S., 1978. The innovation decision in Soviet industry. Cambridge, MA: MIT Press.

Berry, R.A., W.R. Cline, 1979. Agrarian structure and productivity in developing countries. Baltimore, MD: Johns Hopkins University Press.

Bertrand, T.J., J. Vanek, 1971. The theory of tariffs, taxes, and subsidies: some aspects of the second best. The American Economic Review, 61(5), 925-931.

Besley, T.J., H.S. Rosen, 1998. Sales taxes and prices: An empirical analysis. Cambridge, MA: NBER Working Paper No. 6667, 41 pp.

Binswanger, H.P., K.W. Deininger, G. Feder, 1993. Power, distortions, revolt, and reform in agricultural land relations. World Bank Publications, Vol. 1164.

Bird, R., P. Gendron, 2007. The VAT in developing and transitional countries. Cambridge, UK: Cambridge University Press.

Bjerkholt, O., 1998. Ragnar Frisch and the Foundation of the Econometric Society. Statistics Norway Research Department, 36 pp. Available at https://www.ssb.no/a/histstat/doc/doc_199509.pdf.

Blattberg, R.C., K.J. Wisniewski, 1989. Price-induced patterns of competition. Marketing Science, 8(4), 291-309.

Brint, S., 2001. Professionals and the knowledge economy: Rethinking the theory of postindustrial society. Current Sociology, 49(4), 101-132. 
Brown, C., 1999. Minimum wages, employment, and the distribution of income. Handbook of Labor Economics, 3, 2101-2163.

Brown, R.E., 2008a. Electric power distribution reliability. Boca Raton, FL: CRC Press.

Brown, E.H., 2008b. Web of debt: the shocking truth about our money system and how we can break free. Baton Rouge, LA: Third Millennium Press Ltd.

Brown, E.H., 2013. The public bank solution: From austerity to prosperity. Baton Rouge, LA: Third Millennium Press Ltd.

Bube, R., 2012. Fundamentals of solar cells: photovoltaic solar energy conversion. ScienceDirect ${ }^{\circ}$, Elsevier B.V.

Camarda, B., 2001. Using Microsoft Word 2002. Indianapolis, IN: QUE.

Carroll, C.D., L.H. Summers, 1991. Consumption growth parallels income growth: Some new evidence. Cambridge, MA: NBER Working Paper No. 3090, pp. 305-348.

Cassel, G., 1916. The present situation of the foreign exchanges. The Economic Journal, 26(101), 62-65.

Charlier, R.H., C.W. Finkl, 2009. Ocean energy: tide and tidal power. Springer Science \& Business Media.

Chiang, A., K. Wainwright, 2005. Fundamental methods of mathematical economics. New York, NY: McGraw-Hill Publ. Comp.

Chisholm, A.H., 1992. Australian agriculture: a sustainability story. Australian Journal of Agricultural Economics, 36(1), 1-29.

Christiansen, D.S., 2002. Calculus and economics. Tutorial \#1. Available at http://people.albion.edu/ christiansen/micwcalc/screen1.pdf.

Christopher, M., 2005. Logistics and supply chain management: creating value-added networks. Upper Saddle River, NJ: Pearson Education.

Cincotti, S., M. Raberto, A. Teglio, 2012. The Eurace macroeconomic model and simulator. Agentbased Dynamics, Norms, and Corporate Governance. The proceedings of the 16th World Congress of the International Economic Association. New York, NY: Palgrave Macmillan Publisher Ltd.

Clark, C., M.R. Haswell, 1964. The economics of subsistence agriculture. London, UK: Macmillan.

Clover, J., 2003. Food security in sub-Saharan Africa. African Security Studies, 12(1), 5-15.

Conant, R.C., 1991. Laws of information which govern systems. Facets of Systems Science, 419-448.

Congdon, T., 2007. Keynes, the Keynesians and Monetarism. Cheltenham, UK: Edward Elgar Publishing.

Copeland, M.A., 1937. Concepts of national income. Studies in Income and Wealth, 1, 2-63.

Cornia, G.A., 1985. Farm size, land yields and the agricultural production function: An analysis for fifteen developing countries. World Development, 13(4), 513-534.

Coughlan, A.T., R. Lal, 1992. Retail pricing: Does channel length matter? Managerial and Decision Economics, 13(3), 201-214.

Cousin, V., 2011. Banking in China. Palgrave Macmillan Studies in Banking and Financial Institutions. New York, NJ: Palgrave Macmillan Publishers Ltd.

Conzelmann, G., G. Boyd, V. Koritarov, T. Veselka, 2005. Multi-agent power market simulation using EMCAS. Power Engineering Society General Meeting, 2005. IEEE.

Deissenberg, C., S. van der Hoog, H. Dawid, 2008. EURACE: A massively parallel agent-based model of the European economy. Applied Mathematics and Computation, 204(2), 541-552.

Dekeyser, S., R. Watson, 2006. Extending google docs to collaborate on research papers. University of Southern Queensland, Australia. Available at http://citeseerx.ist.psu.edu/viewdoc/ download?doi=10.1.1.90.3176\&rep=rep1\&type=pdf, $11 \mathrm{pp}$.

Deleplace, G., 1996. Money in motion: The Post Keynesian and circulation approaches. New York, NJ: Palgrave Macmillan Publishers Ltd. 
Demirgüç-Kunt, A., H. Huizinga, 1999. Determinants of commercial bank interest margins and profitability: some international evidence. The World Bank Economic Review, 13(2), 379-408.

Devarajan, S., V. Swaroop, H. Zou, 1996. The composition of public expenditure and economic growth. Journal of Monetary Economics, 37(2), 313-344.

Dewenter, K.L., P.H. Malatesta, 1997. Public offerings of state-owned and privately-owned enterprises: an international comparison. The Journal of Finance, 52(4), 1659-1679.

Diamond, J., 1999. Guns, germs, and steel: The fates of human societies. New York, NJ: W.W. Norton \& Company Inc.

Doniec, A., R. Mandiau, S. Piechowiak, S. Espié, 2008. A behavioral multiagent model for road traffic simulation. Engineering Applications of Artificial Intelligence, 21(8), 1443-1454.

Donoso Correa, M.E., 1996. La crisis bananera en el Ecuador de 1991 a 1995. Universidad Católica de Cuenca. Tesis de pregrado, $146 \mathrm{pp}$.

Donoso Correa, M.E., 2000. Análisis de la evolución demográfica del Ecuador 1950-2000. Universidad de Cuenca. Tesis doctoral en Historia y Geografía, 366 pp.

Dooley, M., J. Frankel, D.J. Mathieson, 1987. International capital mobility: What do savinginvestment correlations tell us? Staff Papers-International Monetary Fund, 503-530.

Doutt, J.T., 1984. Comparative productivity performance in fast-food retail distribution. Journal of Retailing, 60(3), 98-106.

Droste, R.L., 1997. Theory and practice of water and wastewater treatment. John Wiley \& Sons, Inc.

Dullien, F.A., 1989. Industrial gas cleaning. Waretown, NJ: Apple Academic Press.

Edwards, S., 1984. Money, the rate of devaluation and interest rates in a semi-open economy: Colombia 1968-1982. Cambridge, MA: NBER Working Paper No. 1380.

Eidson, E.D., M.A. Ehlen, 2005. NISAC agent-based laboratory for economics ( $N$-ABLE $\left.{ }^{\mathrm{TM}}\right)$ : Overview of Agent and Simulation Architectures. Sandia National Laboratories, Technical Report SAND2005-0263.

Elfring, T., 1988. Service sector employment in advanced economies: A comparative analysis of its implications for economic growth. Aldershot, UK: Ashgate Publishing Ltd., 238 pp.

Epstein, J.M., R. Axtell, 1996. Growing artificial societies: social science from the bottom up. Cambridge, MA: The MIT Press.

Erengüç, Ş.S., N.C. Simpson, A.J. Vakharia, 1999. Integrated production/distribution planning in supply chains: An invited review. European Journal of Operational Research, 115(2), 219-236.

European Wind Energy Association, 2009. The economics of wind energy. EWEA. Available at http://www.ewea.org/fileadmin/ewea_documents/documents/publications/reports/Economics_of _Wind_Main_Report_FINAL-lr.pdf, $156 \mathrm{pp}$.

Farmer, J.D., D. Foley, 2009. The economy needs agent-based modelling. Nature, 460(7256), 685-686.

Fehler, M., F. Klügl, F. Puppe, 2004. Techniques for analysis and calibration of multi-agent simulations. Engineering Societies in the Agents World V. Available at https://www.irit.fr/ESAW04/PAPERS/ESAW04_Paper13.pdf, 12 pp.

Feroz, E.H., S. Kim, R.L. Raab, 2003. Financial statement analysis: A data envelopment analysis approach. The Journal of the Operational Research Society, 54(1), 48-58.

Field, C.B., J.E. Campbell, D.B. Lobell, 2008. Biomass energy: the scale of the potential resource. Trends in Ecology \& Evolution, 23(2), 65-72.

Fischer, I., 1997. The works of Irving Fisher. In: Barber, W.J., R.W. Dimand, K. Foster (Eds.) and K. Foster (Consulting Ed.). London, UK: Pickering \& Chatto.

Fischer, S., 1982. Seigniorage and the case for a national money. The Journal of Political Economy, 90(2), 295-313.

Frederiksen, M.W., 1975. Theory, evidence and the ancient economy. Journal of Roman Studies, 65, 164-171. 
Frey, G.W., D.M. Linke, 2002. Hydropower as a renewable and sustainable energy resource meeting global energy challenges in a reasonable way. Energy policy, 30(14), 1261-1265.

Fromm, J., 2006. On engineering and emergence. arXiv preprint nlin/0601002. Availabe at https://arxiv.org/ftp/nlin/papers/0601/0601002.pdf, 11 pp.

Fuchs, V.R., 1968. The service economy. Cambridge, MA: NBER Books.

Gaddis, J. L., 2006. The Cold War: a new history. London, UK: Penguin Group, 333 pp.

Gale, H.F., B. Lohmar, F.C. Tuan, 2005. China's new farm subsidies. USDA-ERS WRS-05-01. Availabe at http://www.ers.usda.gov/media/872040/wrs0501_002.pdf, 16 pp.

Gardner, B.L., 2009. American agriculture in the twentieth century: How it flourished and what it cost. Cambridge, MA: Harvard University Press.

Gilbert, A., 2002. On the mystery of capital and the myths of Hernando de Soto: What difference does legal title make? International Development Planning Review, 24(1), 1-19.

Gilbert, N., P. Terna, 2000. How to build and use agent-based models in social science. Mind \& Society, 1(1), 57-72.

Ghose, A.K., 1979. Farm size and land productivity in Indian agriculture: A reappraisal. The Journal of Development Studies, 16(1), 27-49.

Glaeser, E.L., J. Scheinkman, 1998. Neither a borrower nor a lender be: an economic analysis of interest restrictions and usury laws 1. The Journal of Law and Economics, 41(1), 1-36.

Goolsbee, A., 1998. Does government R\&D policy mainly benefit scientists and engineers? Cambridge, MA: NBER Working Paper No. 6532.

Guala, F., 2008. Experimentation in economics. In: Uskali Mäki (Ed.). Elsevier Handbook of the Philosophy of Science, Vol. 13: Philosophy of Economics.

Greenstein, S.M., P.T. Spiller, 1995. Modern telecommunications infrastructure and economic activity: An empirical investigation. Industrial and Corporate Change, 4(4), 647-665.

Griffin, K., A.R. Khan, A. Ickowitz, 2002. Poverty and the distribution of land. Journal of Agrarian Change, 2(3), 279-330.

Guttmann, R., 2002. Cyber cash: the coming era of electronic money. New York, NJ: Palgrave Macmillan Publishers Ltd.

Hall, R.E., 2009. Introduction to inflation: causes and effects. In: Hall, R.E. (Ed.), Inflation: Causes and Effects. Chicago, IL: University of Chicago Press, 10 pp.

Harrison, M., 2000. The Economics of World War II: Six Great Powers in International Comparison. Cambridge University Press.

Hayami, Y., V.W. Ruttan, 1970. Agricultural productivity differences among countries. The American Economic Review, 60(5), 895-911.

Hayami, Y., 1988. Japanese agriculture under siege: The political economy of agricultural policies. New York, NJ: Palgrave Macmillan Publishers Ltd.

Healy, P., K. Palepu, 2012. Business analysis valuation: Using financial statements. Boston, MA: South-Western Cengage Learning.

Hicks, J.R., 1934. "Léon Walras" Econometrica. Journal of the Econometrica Society, 338-348.

Hicks, J.R., 1963. Theory of wages. Springer.

Hill, J., E. Nelson, D. Tilman, S. Polasky, D. Tiffany, 2006. Environmental, economic, and energetic costs and benefits of biodiesel and ethanol biofuels. Proceedings of the National Academy of Sciences, 103(30), 11206-11210.

Hill, M., J. Toporek, 1979. BMDP statistical software. Dept. of Biomathematics, UCLA, Los Angeles, California, P2V.

Hirsch, A., \& De Marchi, N., 1991. Milton Friedman: Economics in theory and practice. Ann Arbor, MI: University of Michigan Press.

Ho, T.S., A. Saunders, 1981. The determinants of bank interest margins: theory and empirical evidence. Journal of Financial and Quantitative analysis, 16(04), 581-600. 
Holden, C.W., A. Subrahmanyam, 2002. News events, information acquisition, and serial correlation. The Journal of Business, 75(1), 1-32.

Hu, J., 1988. A concise history of Chinese economic thought. Beijing, China: Foreign Languages Press.

Hunt, J., L.F. Katz, 1998. Hours reductions as work-sharing. Brookings Papers on Economic Activity, 1998(1), 339-381.

Hussmanns, R., F. Mehran, V. Varmā, 1990. Surveys of economically active population, employment, unemployment, and underemployment: an ILO manual on concepts and methods. Geneve, Switzerland: International Labour Office. Available at http://www.ilo.org/public/english/bureau/ stat/download/lfs.pdf, $431 \mathrm{pp}$.

Intriligator, M.D., 1971. Mathematical optimization and economic theory. Englewood Cliffs, NJ: Prentice Hall.

Intriligator, M.D., 1978. Econometric models, techniques, and applications. Englewood Cliffs, NJ: Prentice Hall.

Jackson, M.O., 2008. Social and economic networks. Princeton, NJ: Princeton University Press.

Jha, L., K. Jha, 1998. Chanakya: the pioneer economist of the world. International Journal of Social Economics, 25(2/3/4), 267-282.

Kašpar, J., P. Fornasiero, N. Hickey, 2003. Automotive catalytic converters: current status and some perspectives. Catalysis Today, 77(4), 419-449.

Keiser, G., 2003. Optical fiber communications. Encyclopedia of Telecommunications. John Wiley \& Sons, Inc.

Kenessey, Z., 1987. The primary, secondary, tertiary and quaternary sectors of the economy. Review of Income and Wealth, 33(4), 359-385.

Kennedy, J., 1993. Oil and gas pipeline fundamentals. Tulsa, OK: PennWell Books.

Kessides, C., 1993. The contributions of infrastructure to economic development: a review of experience and policy implications. World Bank Discussion Papers, No. WDP 213. Washington D.C.: The World Bank.

Khan, S., 2009. "Poverty reduction efforts: Does microcredit help?" SAIS Review of International Affairs, 29(2), 147-57.

Klein, L.R., 2000. The IS-LM Model: Its role in macroeconomics. In: Recent Economic Thought, pp. 151-159. Springer.

Kobrin, S.J., 1985. Diffusion as an explanation of oil nationalization or the domino effect rides again. Journal of Conflict Resolution, 29(1), 3-32.

Kreps, T., 1935. Dividends, interest, profits, wages, 1923-35^ 1. The Quarterly Journal of Economics, 49(4), 561-599.

Krueger, A.O., 1980. Trade policy as an input to development. The American Economic Review, 70(2), 288-292.

Krueger, A.B., L.H. Summers, 1986. Reflections on the inter-industry wage structure. Cambridge, MA: NBER Working Paper No. 1968.

Kuznets, S., 1937. Appendices to "National income and capital formation, 1919-1935." National Income and Capital Formation, 1919-1935, 61-90.

Langdale, J., 1985. Electronic funds transfer and the internationalisation of the banking and finance industry. Geoforum, 16(1), 1-13.

Landefeld, S.J., E.P. Seskin, B.M. Fraumeni, 2008. Taking the pulse of the economy: Measuring GDP. The Journal of Economic Perspectives, 22(2), 193-193.

Langenhoven, B., M. Dyssel, 2007. The recycling industry and subsistence waste collectors: A case study of Mitchell's plain. Urban Forum, 18(1), 114-132.

Laro, D., S.P. Pratt, 2005. Business valuation and taxes: Procedure, law, and perspective. John Wiley $\&$ Sons, Inc. 
Lee, S., G.D. Holder, 2001. Methane hydrates potential as a future energy source. Fuel Processing Technology, 71(1), 181-186.

Levine, R., S. Zervos, 1998. Stock markets, banks, and economic growth. World Bank Policy Research Working Paper No. 1690; A1.213 Working Paper No. 297. Available at https://papers.ssrn.com/sol3/papers.cfm?abstract_id=60141.

Lin, C., 1973. Industrialization in Taiwan, 1946-72: Trade and import-substitution policies for developing countries. Santa Barbara, CA: Praeger Publishers.

List, F., S. Colwell, 1856. National system of political economy. Philadelphia, PE: JB Lippincott \& Company.

Liu, G., Y. Zhao, 2006. Content, characteristics and formats of industrial chains. The Theory and Practice of Finance and Economics, 3, 022.

Lohse, G.L., P. Spiller, 1998. Electronic shopping. Communications of the ACM, 41(7), 81-87.

Long, C.D., 1952. Professors' salaries and the inflation. Bulletin of the American Association of University Professors (1915-1955), 38(4), 577-588.

Lowry, S.T., 1979. Recent literature on ancient Greek economic thought. Journal of Economic Literature, 17(1), 65-86.

Luenberger, D.G., Y. Ye, 1984. Linear and nonlinear programming. Reading, MA: Addison-Wesley.

Markham, S.K., 2002. Moving technologies from lab to market. Research-Technology Management, 45(6), 31-42.

Mays, L.W., 1999. Water distribution system handbook. New York, NY: McGraw-Hill Publ. Comp.

Mazzucato, M., 2011. The entrepreneurial state. Soundings, 49(49), 131-142.

McLeay, M., A. Radia, R. Thomas, 2014. Money creation in the modern economy. Bank of England Quarterly Bulletin, Q1, 14 pp.

Meade, J.E., 1951. The balance of payments. London, UK: Oxford University Press.

Mearns, R., 1999. Access to land in rural India: policy issues and options. World Bank Publications, Vol. 2123.

Meyers, R.A., 2004. Handbook of petroleum refining processes. New York, NY: McGraw-Hill Publ. Comp.

Miles, D., 1999. Modelling the impact of demographic change upon the economy. The Economic Journal, 109(452), 1-36.

Miller, G.H., E.I. Moses, C.R. Wuest, 2004. The National Ignition Facility: enabling fusion ignition for the 21st century. Nuclear Fusion, 44(12), S228.

Mishkin, F.S., 2007. The economics of money, banking, and financial markets. Upper Saddle River, NJ: Pearson Education.

Morgan, T., 1969. Investment versus economic growth. Economic Development and Cultural Change, 17(3), 392-414.

Mulgan, A.G., 2013. The politics of agriculture in Japan. Abingdon, UK: Routledge Publisher.

Müller-Steinhagen, H., F. Trieb, 2004. Concentrating solar power. A review of the Technology. Ingenia Inform QR Acad Eng, 18, 43-50.

Mundell, R., 1963. Inflation and real interest. The Journal of Political Economy, 71(3), 280-283.

Naghshpour, S., 2012. Regression for economics. New York, NY: Business Expert Press.

Nevins, A., J.D. Rockefeller, 1940. John D. Rockefeller: The heroic age of American enterprise. Allan Nevins and Charles Scribner's Sons. Princeton University, Library. Dept. of Rare Books and Special Collections.

Newton, I., 1979. Opticks, or, a treatise of the reflections, refractions, inflections \& colours of light ( $4^{\text {th }}$ ed.). London, UK: Courier Corporation.

Nicholson, H.N., 2000. People, land and time: An historical introduction to the relations between lanscape, culture and environment. The Geographical Journal, 166, 267. 
Nikolai, C., G. Madey, 2009. Tools of the trade: A survey of various agent based modeling platforms. Journal of Artificial Societies and Social Simulation, 12(2), 2.

Niroula, G.S., G.B. Thapa, 2005. Impacts and causes of land fragmentation, and lessons learned from land consolidation in South Asia. Land Use Policy, 22(4), 358-372.

Novikov, I., 1958. The efficiency of atomic power stations (a review). Journal of Nuclear Energy, 7(1), 125-128.

OECD, 2013. Stat-Extracts. Country statistical profiles. Production and income. Available at https://stats.oecd.org/Index.aspx?DataSetCode=CSP2012.

OECD, 2016. Regional well-being - How is life? Available at https://www.oecdregionalwellbeing.org/.

Obstfeld, M., K.S. Rogoff, 1996. Foundations of international macroeconomics (Vol. 30). Cambridge, MA: MIT Press.

Ohlin, B., 1952. Interregional and international trade. Cambridge, MA: Havard University Press.

Okun, A.M., 1981. Prices and quantities: A macroeconomic analysis. Washington D.C.: Brookings Institution Press.

Ott, I., 2006. Bureaucracy, tax system, and economic performance. Journal of Public Economic Theory, 8(5), 839-862.

Petty, W., 1755. Several essays in political arithmetic. London, UK: Routledge, Thoemmes Press.

Piketty, T., A. Goldhammer, L. Ganser, 2014. Capital in the twenty-first century. Grand Haven, Michigan: Brilliance Audio.

Polinsky, A.M., S. Shavell, 2000. The economic theory of public enforcement of law. Journal of Economic Literature, 38, 45-76.

Porket, J.L., 1989. Work, employment and unemployment in the Soviet Union. New York, NJ: Palgrave Macmillan Publishers Ltd.

Porter, M.E., 2008. On competition. Brighton, MA: Harvard Business Press.

Poos, L.R., 1983. The social context of Statute of Labourers enforcement. Law and History Review, 1(01), 27-52.

Quesnay, F., 1972. Quesnay's tableau économique [1759]. In: Kuczynski, M., R.L. Meek (Eds.). London, UK: Macmillan Publishers Ltd.

Radakovits, R., R.E. Jinkerson, A. Darzins, M.C. Posewitz, 2010. Genetic engineering of algae for enhanced biofuel production. Eukaryotic Cell, 9(4), 486-501.

Regmi, M.C., 1976. Landownership in Nepal. Berkeley, CA: University of California Press.

Richardson, K.A., 2003. On the limits of bottom-up computer simulation: Towards a nonlinear modeling culture. System Sciences, 2003. Proceedings of the 36th Annual Hawaii International Conference On. IEEE.

Rizov, M., J. Pokrivcak, P. Ciaian, 2013. CAP subsidies and productivity of the EU farms. Journal of Agricultural Economics, 64(3), 537-557.

Roth, J.D., 1997. The limits of micro credit as a rural development intervention. University of Manchester, Manchester, UK.

Ross, M., 2012. The oil curse: how petroleum wealth shapes the development of nations. Princeton, NJ: Princeton University Press.

Rubinstein, A., 1990. Game theory in economics. Northampton, MA: Edward Elgar Publishing.

Rugman, A.M., 1981. Inside the multinationals: The economics of internal markets. New York, NY: Columbia University Press.

Ruiz Martín, P., 2013. Presente y futuro de los Massive Open Online Courses (MOOC): Análisis de la oferta completa de cursos de las plataformas Coursera, EdX, Miríada X y Udacity. Madrid, España: Universidad Complutense. Available at http://eprints.ucm.es/23502/.

Salter, W.E.G., 1966. Productivity and technical change, with addendum by W.B. Reddaway. Cambridge, UK: Cambridge University Press. 
Saunders, A., M.M. Cornett, P.A. McGraw, 2006. Financial institutions management: A risk management approach. Columbus, OH: McGraw-Hill Higher Education.

Schäfer, S., P. Kolkhof, 2008. Failure is an option: learning from unsuccessful proof-of-concept trials. Drug Discovery Today, 13(21), 913-916.

Scheinkman, J.A., W. Xiong, 2003. Overconfidence and speculative bubbles. Journal of Political Economy, 111(6), 1183-1220.

Schwartz, G., B. Clements, 1999. Government subsidies. Journal of Economic Surveys, 13(2), 119-148.

Shapere, D., 1982. The concept of observation in science and philosophy. Philosophy of Science, 49(4), 485-525.

Shiller, R.J., 2015. Irrational exuberance. Princeton, NJ: Princeton University Press.

Sims, C.A., 1980. Macroeconomics and reality. Econometrica: Journal of the Econometric Society, $48(1), 1-48$.

Singer, J.G., 1981. Combustion, fossil power systems: a reference book on fuel burning and steam generation $\left(3^{\text {rd }}\right.$ ed.). Windsor, CT (1000 Prospect Hill Rd., Windsor 06095): Combustion Engineering.

Scrosati, B., J. Hassoun, Y. Sun, 2011. Lithium-ion batteries. Look into the future. Energy \& Environmental Science, 4(9), 3287-3295.

Skolnikoff, E.B., 1994. The elusive transformation: science, technology, and the evolution of international politics. Princeton, NJ: Princeton University Press.

Smith, L., 1980. Covert British Propaganda: The information research department: 1947-771. Millennium-Journal of International Studies, 9(1), 67-83.

Soroka, S.N., 2006. Good news and bad news: Asymmetric responses to economic information. Journal of Politics, 68(2), 372-385.

Starosta, G., 2015. Marx's capital, method and revolutionary subjectivity. Leiden, The Netherlands: BRILL Publishers.

Stockhammer, E., 2013. Why have wage shares fallen. ILO, Conditions of Work and Employment Series, 35, $61 \mathrm{pp}$.

Stull, W.J., 1974. Land use and zoning in an urban economy. The American Economic Review, 64(3), 337-347.

Sumerlin, M., L.M. Katzovitz, 2007. Collateralized debt obligations. The Magazine of International Economic Policy, 12-14.

Swamidass, P.M., S. Kotha, 1998. Explaining manufacturing technology use, firm size and performance using a multidimensional view of technology. Journal of Operations Management, 17(1), 23-37.

Tai, H., 1974. Land reform and politics: a comparative analysis. Berkeley, CA: University of California Press.

Tait, A.A., 1988. Value added tax: International practice and problems. International Monetary Fund, $450 \mathrm{pp}$.

Taslim, M.A., 1989. Supervision problems and the size-productivity relation in Bangladesh agriculture. Oxford Bulletin of Economics and Statistics, 51(1), 55-71.

Tchobanoglous, G., F.L. Burton, H.D. Stensel, 1991. Wastewater engineering: Treatment and reuse. Metcalf \& Eddy, Inc., 21 pp.

Tesfatsion, L., K.L. Judd, 2006. Handbook of computational economics: agent-based computational economics. In: Tesfatsion, L., K.L. Judd (Eds.). Handbook of Computational Economics, Vol. 2, pp. 829-1660, I1-I38.

Tisue, S., U. Wilensky, 2004. Netlogo: A simple environment for modeling complexity. Boston, MA: Presented at the International Conference on Complex Systems, Boston, May 16-21, 2004. 
Towill, D.R., 1996. Industrial dynamics modelling of supply chains. International Journal of Physical Distribution \& Logistics Management, 26(2), 23-42.

Trotsky, L., \& Eastman, M., 2008. History of the Russian revolution. Chicago, IL: Haymarket Books.

Urday, W.M., 2011. La economía conductual y el análisis experimental del comportamiento de consumo. Revista de Investigación en Psicología, 14(1), 281-292.

Van Helden, A., 1977. The invention of the telescope. Transactions of the American Philosophical Society, 67(4), 1-67.

Vives, X., 1984. Duopoly information equilibrium: Cournot and Bertrand. Journal of Economic Theory, 34(1), 71-94.

Walters, A.A., 1967. The demand for money-the dynamic properties of the multiplier. The Journal of Political Economy, 75(3), 293-298.

Wapshott, N., 2011. Keynes Hayek: The clash that defined modern economics. W.W. Norton \& Company.

Wei, S., T. Wang, 1997. The Siamese twins: Do state-owned banks favor state-owned enterprises in China? China Economic Review, 8(1), 19-29.

Weiland, P., 2010. Biogas production: current state and perspectives. Applied Microbiology and Biotechnology, 85(4), 849-860.

Weingast, B.R., 1995. The economic role of political institutions: Market-preserving federalism and economic development. Journal of Law, Economics, \& Organization, 11(1), 1-31.

Weisstein, E.W., 2005. Moore neighborhood. From MathWorld-A Wolfram Web Resource. Available at http://mathworld. wolfram.com/MooreNeighborhood.html.

Weintraub, E.R., 2008. Mathematics and economics. In: Durlauf, S.N., L.E. Blume (Eds.). The New Palgrave Dictionary of Economics ( $2^{\text {nd }}$ ed.). New York, NJ: Palgrave Macmillan Publishers Ltd.

Whittingham, M.S., 2008. Inorganic nanomaterials for batteries. The International Journal for Inorganic, Organometallic and Bioinorganic Chemistry, 40, 5424-5431.

Widmaier, H.P., J. Frank, O. Roloff, 1972. Public expenditure and private consumption. Springer Link, Chapter: The Future is Tomorrow, pp 348-370.

Wiedemann, H., 2015. Particle accelerator physics. Springer.

Wilson, C., 1995. The invisible world: early modern philosophy and the invention of the microscope (Vol. 228). Princeton, NJ: Princeton University Press.

Wolfe, M., 1955. The concept of economic sectors. The Quarterly Journal of Economics, 69(3), 402-420.

Wolfram, S., 1983. Statistical mechanics of cellular automata. Reviews of Modern Physics, 55(3), 601-644.

Woolsey, L.H., 1938. The expropriation of oil properties by Mexico. The American Journal of International Law, 32(3), 519-526.

World Bank Group, 2012. World development indicators 2012. New York, NY: World Bank Publications.

Wurman, P.R., R. D'Andrea, M. Mountz, 2008. Coordinating hundreds of cooperatives, autonomous vehicles in warehouses. AI Magazine, 29(1), 9-20.

Xianhui, B., W. Liansheng, 2009. The governance roles of state-owned controlling and institutional investors: A perspective of earnings management. Journal of Finance and Economics, 2009-01.

Yaron, J., 1994. Successful rural finance institutions. Finance and Development, 31(1), 32. 